Artigo

\title{
Análise do Sequestro de Carbono em Áreas de Caatinga do Semiárido Pernambucano
}

\author{
Ygor Cristiano Brito Morais ${ }^{1}$, Maria do Socorro Bezerra de Araújo ${ }^{2}$, \\ Magna Soelma Beserra de Moura ${ }^{3}$, Josiclêda Domiciano Galvíncio², \\ Rodrigo de Queiroga Miranda ${ }^{1}$ \\ ${ }^{1}$ Programa de Pós-Graduação em Desenvolvimento e Meio Ambiente, \\ Universidade Federal de Pernambuco, Recife, PE, Brasil. \\ ${ }^{2}$ Departamento de Ciências Geográficas, Universidade Federal de Pernambuco, \\ Recife, PE, Brasil. \\ ${ }^{3}$ Empresa Brasileira de Pesquisa Agropecuária, Unidade Semiárido, Petrolina, PE, Brasil.
}

Recebido em 15 de abril de 2016 - Aceito em 31 de dezembro de 2016/

\begin{abstract}
Resumo
Diante do aumento das emissões dos gases do efeito estufa, o presente estudo analisou o sequestro de carbono em áreas de caatinga do município de Petrolina - PE, por meio de técnicas de sensoriamento remoto. Foram utilizadas imagens do sensor MODIS, referentes ao produto MOD17, o qual contém a estimativa da Produção primária bruta (GPP) e da Produção primária líquida (NPP). A coleta das imagens ocorreu para os anos de 2011 e 2012. No período chuvoso, as áreas de caatinga preservada apresentaram maiores valores de assimilação total (até $160 \mathrm{~g} \mathrm{C} / \mathrm{m}^{2}$ em janeiro de 2011) e sequestro de carbono, enquanto no final do período seco foram registrados valores inferiores a $20 \mathrm{~g} \mathrm{C} / \mathrm{m}^{2}$. Quanto ao total anual, em 2011 as áreas de caatinga preservada juntamente com a agricultura irrigada apresentaram os maiores valores de GPP (>900 g C/m²), enquanto que em 2012 a GPP das áreas de caatinga variaram, em geral, de 500 a $600 \mathrm{~g} \mathrm{C} / \mathrm{m}^{2}$, com algumas áreas chegando a $700 \mathrm{~g} \mathrm{C} / \mathrm{m}^{2}$. A NPP, ou seja, o sequestro de carbono, variou de 500 a $700 \mathrm{~g} \mathrm{C} / \mathrm{m}^{2}$ em 2011 e de 100 a $400 \mathrm{~g} \mathrm{C} / \mathrm{m}^{2}$ em 2012. Desse modo, são necessárias medidas e elaboração de instrumentos políticos que visem à preservação dos remanescentes de caatinga do município de Petrolina, como forma de contribuir com mitigação do aquecimento global.
\end{abstract}

Palavras-chave: mudanças climáticas, semiárido, sensoriamento remoto, sequestro de carbono, vegetação.

\section{Analysis of Carbon Sequestration in Caatinga Areas of Pernambucano Semiarid}

\begin{abstract}
Given the increasing emissions of greenhouse gases, the present study analyzed the carbon sequestration in savanna areas of the city of Petrolina - PE, via remote sensing techniques. Images from the MODIS sensor, for the product MOD17, which contains an estimated gross primary production (GPP) and net primary production (NPP). The collection of images was for the years 2011 and 2012. During the rainy season, the preserved savanna areas had higher overall assimilation of values (up to $160 \mathrm{~g} \mathrm{C} / \mathrm{m}$ in January 2011) and carbon sequestration, however the dry season stood out areas of irrigated agriculture. As the annual total in 2011 the areas of savanna preserved along with irrigated agriculture had the highest GPP values $\left(>900 \mathrm{~g} \mathrm{C} / \mathrm{m}^{2}\right)$, while in 2012 the GPP of savanna areas ranged generally from 500 to $600 \mathrm{~g} \mathrm{C} / \mathrm{m}^{2}$, with some areas reaching $700 \mathrm{~g} \mathrm{C} / \mathrm{m}^{2}$. The NPP, ie carbon sequestration, ranged 500-600 g C/m in 2011 and $400 \mathrm{~g} \mathrm{C} / \mathrm{m}^{2}$ in 2012. Thus, measures are needed and development of policy instruments aimed at the conservation of remaining to scrub the city of Petrolina, in order to contribute to mitigating global warming.
\end{abstract}

Keywords: climate change, semiarid, remote sensing, carbon sequestration, vegetation.

Autor de correspondência: Ygor Cristiano Brito Morais, ygor.cmorais@gmail.com. 


\section{Introdução}

Mudanças no sistema climático da Terra são consideradas processos naturais em escala de tempo geológico (Spielhagen, 2012). Entretanto, a velocidade e intensidade com as quais essas mudanças estão ocorrendo, especialmente quando somadas às várias ações antrópicas danosas ao planeta, têm sido objetos de preocupação nos domínios da ciência e política mundiais (Koehler et al., 2002, Galvíncio et al., 2011). Cientistas de todo o mundo têm alertado para o aumento das emissões dos gases de efeito estufa (GEE), pois estes interferem no balanço radiativo da atmosfera, e estão levando, em longo prazo, a um aumento da temperatura média da terra (Koehler et al., 2002). Estudos compilados pelo Painel Intergovernamental sobre Mudanças Climáticas - IPCC afirmam que a concentração de dióxido de carbono $\left(\mathrm{CO}_{2}\right)$ na atmosfera subiu de cerca de 280 partes por milhão (ppm), em 1750, para os 392 ppm, em 2011 (IPCC, 2014). As maiores fontes antrópicas de emissões de GEE's, especialmente de $\mathrm{CO}_{2}$, são a queima de combustíveis fósseis, os desmatamentos, as queimadas, a pecuária extensiva, entre outros (Koehler et al., 2002).

$\mathrm{O}$ aumento das emissões dos GEEs vem acarretando na busca por alternativas que visem à redução das fontes desses gases (Carvalho et al., 2010), dentre as quais se destacam melhorias na eficiência energética, produção em larga escala de biocombustíveis e o reflorestamento - para aumentar o potencial de sequestro de carbono (Schaeffer $e t$ al., 2006). O sequestro de carbono pode ser definido como o processo segundo o qual o carbono é removido da atmosfera e incorporado/armazenado na biomassa vegetal (Lal, 2008; Silva, 2012), sendo seu conceito consagrado a partir da ratificação do Protocolo de Kyoto, durante a Conferência das Partes realizada em 1997, na cidade de Kyoto. O protocolo visou o estabelecimento de metas de redução das emissões dos GEEs por parte dos países industrializados. Além disso, foram estabelecidos três mecanismos adicionais de implementação, como forma de flexibilização para se atingir as metas de redução, com destaque para os Mecanismos de Desenvolvimento Limpo - MDL (MCT, 2009), onde está inserido o sequestro de C. Este pode ser alcançado através do aumento das áreas plantadas, a recuperação de áreas degradadas e a proteção das florestas (Silva et al., 2013).

No Brasil, em 2009, foi instituída a Política Nacional sobre Mudança do Clima (PNMC), resultado do compromisso assumido junto à Convenção-Quadro da Organização das Nações Unidas sobre Mudança do Clima de redução de emissões de gases de efeito estufa entre $36,1 \%$ e $38,9 \%$ das emissões projetadas até 2020 , cujo valor estipulado situa-se entre 1,168 gigatonelada de $\mathrm{CO}_{2}$ e $1,259 \mathrm{Gt}$ $\mathrm{CO}_{2}$ (MCTI, 2014). Além disso, o artigo $4^{\circ}$ da PNMC prevê o fortalecimento das remoções antrópicas por sumidouros de gases do efeito estufa no território nacional, bem como à conservação e à recuperação dos recursos ambientais, sobretudo os grandes biomas naturais Lei Federal $\mathrm{n}^{\circ}$ 12.187, de 29 de dezembro de 2009 (BRASIL, 2009). Dessa forma, torna-se essencial o conhecimento sobre os fluxos e estoques de carbono nos principais biomas brasileiros sobretudo aqueles mais vulneráveis.

Estudos recentes destacam que o semiárido brasileiro será a região do país mais afetada pelas mudanças climáticas, com possibilidade de aumento da temperatura do ar de 2 a $4{ }^{\circ} \mathrm{C}$ até o final deste século (Marengo, 2008). Nessa região se destaca a Caatinga, ecossistema tipicamente brasileiro, constituído por um complexo vegetacional que abrange uma área de aproximadamente 800.000 $\mathrm{km}^{2}$ (Santos et al., 2011), com florestas arbóreas ou arbustivas, compreendendo principalmente árvores e arbustos baixos muitos dos quais apresentam espinhos, microfilia e características xerofíticas (Giongo et al., 2011). As plantas da caatinga possuem seu comportamento fisiológico e fenológico adaptados às condições de clima adverso, e seus recursos naturais são utilizados como fonte de sobrevivência para uma parte da população local (Trovão et al., 2007).

Entretanto, os recursos naturais e a biodiversidade do bioma caatinga se encontram, atualmente, ameaçados por diversos processos de degradação. Nessa região vivem aproximadamente 27 milhões de pessoas (Gariglio et al., 2010), das quais muitas praticam agricultura de corte-equeima ou pecuária, convertendo a vegetação nativa em terras agrícolas de curta duração, ou pasto para gado e caprinos (Santos e Tabarelli, 2002; Mittermeier et al., 2003; Souza et al., 2015). Em 1984, a cobertura do Bioma Caatinga foi estimada em $68 \%$ de sua vegetação remanescente, sendo $32 \%$ de áreas antropizadas, ou seja, espaços ocupados por agricultura ou alterados pela ação humana (CNRBC, 2004). Em 2008, o Projeto de Conservação e Utilização Sustentável da Diversidade Biológica Brasileira - PROBIO publicou um trabalho com o mapeamento das áreas remanescentes de caatinga, e estas de acordo com os resultados, consistiam em $43 \%$ da área total. Contudo, a degradação potencial ainda é maior, uma vez que em escala regional, estima-se que cerca de $70 \%$ da caatinga já se encontram alterados pelo homem (Araújo, 2007), e somente $1 \%$ de sua área está protegida através de Unidades de Conservação de Proteção Integral, e 6,4\% por Unidades de Conservação de Uso Sustentável (MMA, 2010).

De forma mais específica, as atividades antrópicas na região semiárida vêm modificando os padrões regionais do clima, a disponibilidade hídrica, a disponibilidade de nutrientes e consequentemente a biodiversidade, e assim configurando um ambiente em que os balanços de GEE's e energia se encontram totalmente modificados (Santos e Tabarelli, 2002). O resultado disso é um ecossistema que talvez esteja agindo mais como fonte de GEE's do que como sumidouro. Portanto, muitos pesquisadores acreditam que ações que visam às reduções das emissões de gases do efeito estufa devem ser imediatamente colocadas em prática para garantir a resiliência desse importante ecossis- 
tema frente às oscilações climáticas atuais (Marengo, 2008; Alves e Diniz, 2009; Angelotti et al., 2011; Barros, 2011).

Desse modo, o presente trabalho tem como objetivo analisar o sequestro de carbono em áreas de caatinga localizadas no município de Petrolina, Estado de Pernambuco, buscando contribuir com o conhecimento a respeito do sequestro de carbono pelo bioma caatinga, que se encontra atualmente ameaçado em decorrência da degradação ambiental.

\section{Material e Métodos}

\subsection{Localização e caracterização da área de estudo}

A presente pesquisa tem como área de estudo o município de Petrolina, com sede localizada nas coordenadas 9॰23'54" S e 40³0'02" O (Fig. 1), estando inserido na mesorregião do São Francisco do Estado de Pernambuco e microrregião que recebe seu nome. Segundo o Instituto Brasileiro de Geografia e Estatística - IBGE (2010), o município de Petrolina possui população total de 293.962 habitantes, sendo $74,6 \%$ deste total residente em áreas urbanas.

No tocante a climatologia do município de Petrolina, a variação sazonal da precipitação mostra-se bastante irregular, com o período chuvoso se iniciando em novembro e se estendendo até abril, assim como ocorre na maior parte do Sertão nordestino (Santos et al., 2013). Enquanto isso, os meses subsequentes se evidenciam extremamente secos, pois a precipitação acumulada neste período representa apenas $12,7 \%$ do total anual. A temperatura do ar média do município de Petrolina é maior nos meses de outubro $\left(27,5^{\circ} \mathrm{C}\right)$ e novembro $\left(27,3^{\circ} \mathrm{C}\right)$, período correspondente ao final da estação chuvosa. Por outro lado, a temperatura mais baixa é registrada no mês de julho, atingindo $23,9^{\circ} \mathrm{C}$ (EMBRAPA, 2013).

O Uso e Cobertura da Terra do município de Petrolina (Fig. 2) se caracterizam pela presença de uma vegetação do tipo Savana Estépica Arborizada, Agropecuária (agricultura de sequeiro e irrigada), áreas de Savana Estépica arborizada com presença de agropecuária, conforme mapeamento realizado pelo Projeto de Conservação e Utilização Sustentável da Diversidade Biológica Brasileira - PROBIO (2008).

A Savana estépica arborizada está estruturada em um estrato arbustivo-arbóreo-superior, sendo esparso e geralmente de características idênticas ao da Savana Estépica Florestada, e outo inferior, gramíneo-lenhoso (IBGE, 2012). Essa classe corresponde à caatinga arborizada que se encontra mais preservada, com pouca influência das atividades antrópicas. Enquanto isso, a região de Savana estépica arborizada com agropecuária corresponde à classe de mapeamento em que a atividade agropecuária se faz presente, provocando, em algumas áreas, mudanças na composição e estrutura da vegetação. Neste trabalho a região de Savana estépica arborizada com agropecuária foi considerada como caatinga antropizada.

A agricultura irrigada está representada pelos perímetros irrigados Nilo Coelho e de Bebedouro. Este de tipo
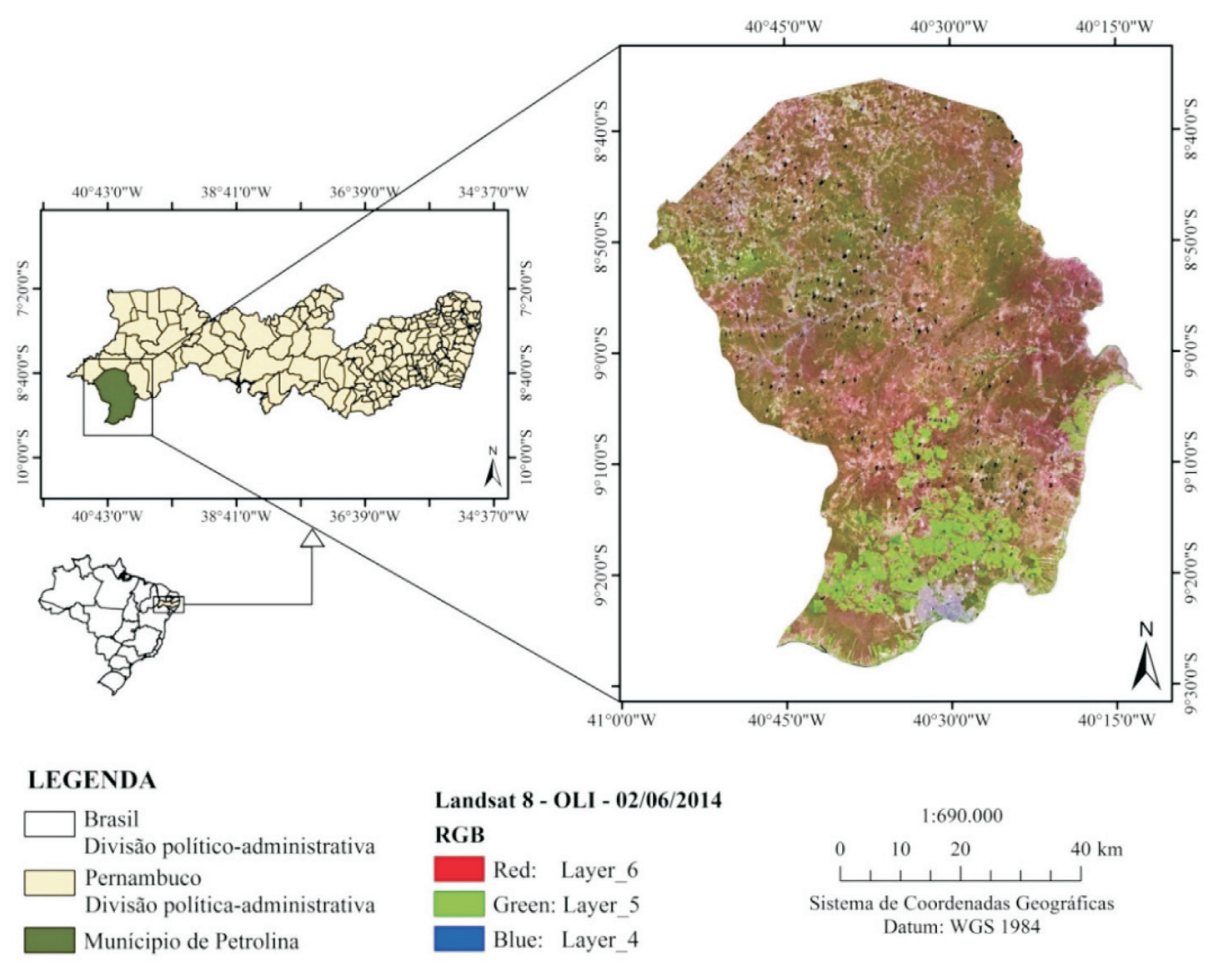

Figura 1 - Localização geográfica do município de Petrolina - PE. 


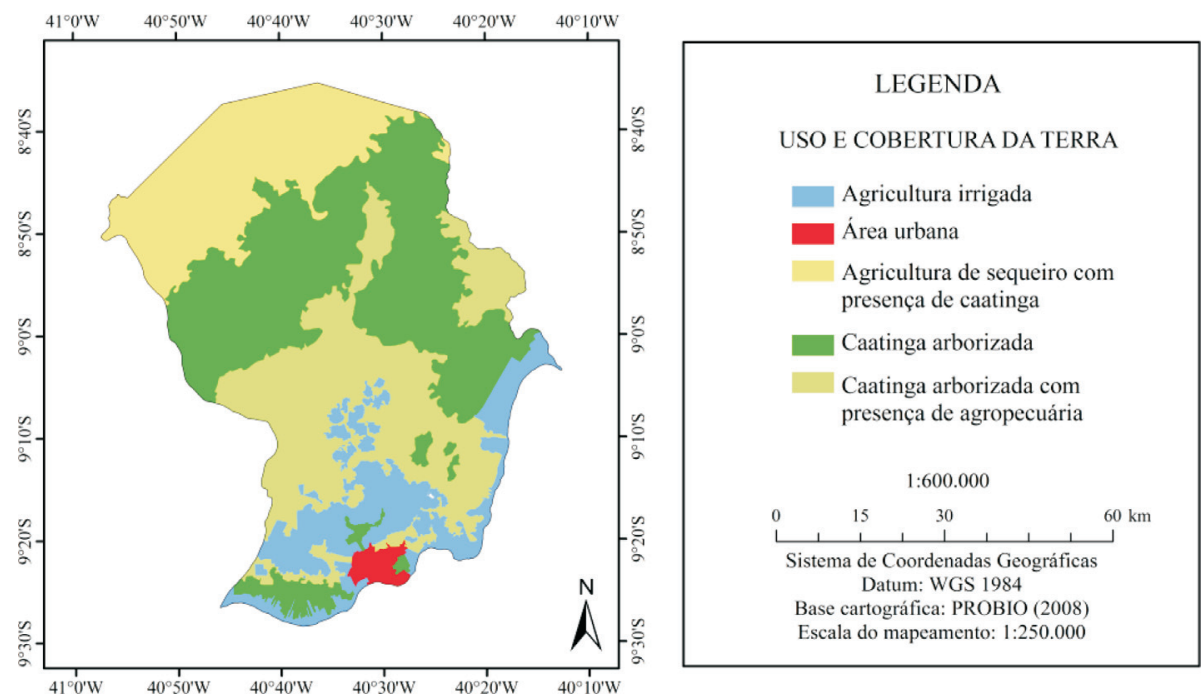

Figura 2 - Uso e cobertura da terra do município de Petrolina - PE. Fonte: Adaptado PROBIO (2008).

de agricultura foi impulsionada a partir da construção de diversas barragens ao longo do curso do rio São Francisco, em especial a barragem de Sobradinho no final da década de 1970 (Andrade, 2005). O perímetro irrigado Senador Nilo Coelho possui $80 \%$ de duas terras inseridas no município de Petrolina, possuindo uma área irrigável total de aproximadamente 22.949 hectares. Além disso, possui 2.082 pequenos produtores com lotes familiares (até $7 \mathrm{ha}$ ), 227 pequenas, médias e grandes empresas (acima de 50 ha), tendo com principais culturas a manga $(38,42 \%$ da área total), uva $(22,6 \%)$ e goiaba $(9,8 \%)$ (DNIC, 2014$)$.

\subsection{Metodologia}

Neste estudo foram utilizados produtos do Sensor MODIS, a bordo do satélite Terra, com resolução espacial de 1 quilômetro e resolução temporal de oito dias, referentes aos anos de 2011 e 2012. O produto utilizado foi o MOD17, que contém a produção primária bruta ( $G P P$, em inglês) e líquida ( $N P P$, em inglês) das superfícies vegetadas. Estes produtos estão disponíveis na página eletrônica do Serviço Geológico dos Estados Unidos (USGS). Os produtos MODIS de ecossistemas terrestres estão disponíveis na projeção sinusoidal (SIN) e são divididos em quadrantes (tiles, em inglês) de $10 \times 10$ graus, ou seja, $1200 \times 1200 \mathrm{~km}$.

\subsubsection{Produto MOD17 (Produção primária bruta e líquida)}

O produto MOD17 possui três camadas, sendo elas a produção primária líquida, produção primária bruta, e a de qualidade do pixel. Este produto é disponibilizado pelo USGS e consiste no somatório de 8 dias da GPP e $N P P$ diárias. Cada soma corresponde ao período de 8 dias consecutivos a partir da data de disponibilização, sendo ao todo 46 imagens/somas criadas para cada ano. Para obter a estimativa da GPP/NPP diária para o período de oito dias, é necessário dividir o valor por oito para os primeiros 45 valores do ano e por cinco (ou seis no caso de anos bissextos) para o período final.

O algoritmo usado pela USGS para estimar a produção primária bruta $(G P P)$ utiliza a relação entre a Radiação Fotossinteticamente Ativa e a Eficiência no Uso da Luz, utilizando-se dados meteorológicos globais e informações obtidas por meio de sensoriamento remoto, de acordo com a seguinte equação:

$$
G P P=\varepsilon \times f P A R \times P A R
$$

onde $\varepsilon$ é a eficiência do uso da luz, $f P A R$ é a fração da radiação fotossitenticamente ativa absorvida pelos dosséis e $P A R$ é a densidade do fluxo de radiação fotossinteticamente ativa $\left(\mathrm{MJ} \mathrm{m}^{-2} \mathrm{dia}^{-1}\right)$.

A estimativa da produção primária bruta depende de parâmetros de entradas de três fontes. Primeiro, os dados meteorológicos de grande escala são fornecidos pelo Escritório de Assimilação de Dados da NASA. Os dados fornecidos pelo DAO incluem temperatura média e mínima do ar, radiação fotossinteticamente ativa incidente e umidade relativa. Tais dados são produzidos a cada seis horas e são derivados de um Modelo de Circulação Global (GCM), que incorpora dados de superfície e de observações por satélite, sendo distribuídos com uma resolução espacial de $1^{\circ}$ por $1,25^{\circ}$. Segundo, o cálculo da $\varepsilon$ utiliza constantes especificas baseadas em 8 classes de biomas presentes no produto de cobertura da terra do MODIS. Por último, o terceiro conjunto de dados é derivado da estimativa da $P P A R$ diária, utilizando dados de cobertura da terra e as refletâncias de superfície corrigidas atmosfericamente e com resolução de $1 \mathrm{~km}$ (Heincsh et al., 2003).

Algumas simplificações do algoritmo do MOD17/GPP podem provocar erros que estão relacionados com as três principais fontes de entrada de dados, sendo elas: (1) meteorologia, (2) radiometria e (3) parâmetros biofísicos. Sendo assim, erros relacionados a meteorologia 
decorrem da resolução espacial baixa dos dados $\left(1^{\circ} \times 1,25^{\circ}\right)$. No que se refere a radiometria, os erros estão relacionados ao cálculo do $f P A R$, que considera o valor máximo do $f P A R$ para o período de oito dias, enquanto as estimativas de $G P P$ são diárias. E, por fim, a lógica do algoritmo da $G P P$ considera que os parâmetros biofísicos específicos de cada bioma não variam no tempo e no espaço. Além disso, tais parâmetros não variam de acordo com as variações fisionômicas existentes em um mesmo bioma. Com isso, erros em qualquer um dos parâmetros de entrada citados pode levar a inconsistências na estimativa da GPP (Heincsh et al., 2003).

\section{Resultados e Discussão}

\subsection{Variabilidade mensal da precipitação entre os anos de 2011 e 2012}

O semiárido brasileiro apresenta alta variabilidade da precipitação, condicionando, assim, o comportamento fenológico da vegetação. Por isso, o entendimento da mesma é essencial para compreensão da variação temporal/sazonal do sequestro de carbono na caatinga. Nesse sentido, a Fig. 3 evidencia a precipitação acumulada mensal dos anos 2011 e 2012.

Nota-se que no ano de 2011 as chuvas estiveram próximo a média histórica $(514 \mathrm{~mm})$, sendo abril o mês mais chuvoso, com 127,6 mm. Em contrapartida, no ano de 2012, a precipitação anual foi de $130,5 \mathrm{~mm}$, valor este quatro vezes menor que a média histórica. A precipitação mais alta foi registrada no mês de fevereiro $(75,6 \mathrm{~mm})$. Ou seja, o ano de 2012 foi extremamente seco.

\subsection{Variação mensal do sequestro de carbono entre os anos de 2011 e 2012}

A variação mensal da produção primária bruta do município de Petrolina para o ano de 2011 (Fig. 4) foi influenciada pela sazonalidade da precipitação pluviométrica, contudo é possível verificar diferenças na resposta da $G P P$ de acordo com o uso e cobertura da terra. Nesse sentido, os valores mais elevados de $G P P$ para a área de caatinga foram registrados no mês de janeiro, atingindo valores superiores a $160 \mathrm{~g} \mathrm{C} / \mathrm{m}^{2}$. Em fevereiro constatou-se uma redução na assimilação de carbono pela caatinga, mas nos meses seguintes houve uma recuperação desses valores. Nota-se, ainda, que a partir do mês de abril, ainda no período chuvoso, as áreas de caatinga antropizada localizadas na porção sudeste do município assimilaram menos carbono (40 a $50 \mathrm{~g} \mathrm{C} / \mathrm{m}^{2}$ ), em comparação com as demais áreas. Com o início da estação seca (em maio), a GPP apresenta redução nas áreas de caatinga e de agropecuária com presença de caatinga, atingindo valores inferiores a $30 \mathrm{~g} \mathrm{C}^{2} \mathrm{~m}^{2}$ ao término do período seco. Nesse período, tem-se como destaque a agricultura irrigada, na qual a $G P P$ permanece elevada, com valores variando de 40 a $100 \mathrm{~g} \mathrm{C} / \mathrm{m}^{2}$. Em novembro e dezembro, a GPP das áreas de

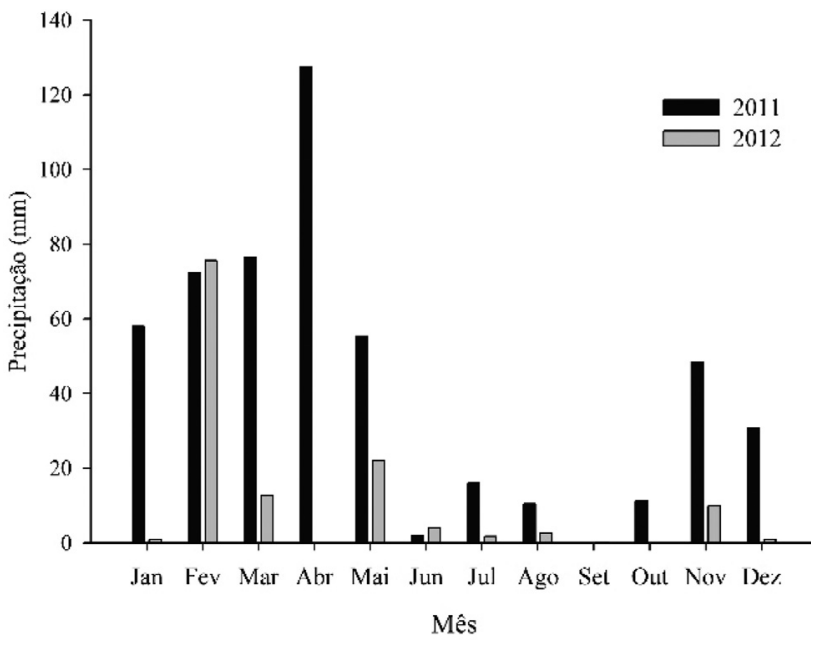

Figura 3 - Precipitação pluviométrica acumulada mensal dos anos 2011 e 2012, para a estação meteorológica localizada em área de caatinga no município de Petrolina - PE.

caatinga apresentou um aumento, com predomínio de valores de 60 a $80 \mathrm{~g} \mathrm{C} / \mathrm{m}^{2}$.

No ano de 2012, a variação mensal da assimilação de carbono apresentou características diferentes em relação ao ano anterior, sobretudo nas áreas com cobertura da caatinga e durante o período chuvoso. Com isso, observa-se que a $G P P$ das áreas de caatinga mais preservadas (noroeste do município) apresentou valores, em geral, entre 60 e $80 \mathrm{~g} \mathrm{C} / \mathrm{m}^{2}$, correspondendo a cerca da metade da quantidade de carbono assimilada no mesmo período do ano anterior (Fig. 5). Nas áreas de caatinga com presença de agropecuária a $G P P$ foi mais baixa, com valores inferiores a $40 \mathrm{~g} \mathrm{C} / \mathrm{m}^{2}$. Em fevereiro e março houve um aumento da $G P P$ por parte da vegetação nativa, sendo que algumas localidades registraram GPP entre 120 e $140 \mathrm{~g} \mathrm{C} / \mathrm{m}^{2}$, entretanto em todo município predominou valores que variam de 60 a $80 \mathrm{~g} \mathrm{C} / \mathrm{m}^{2}$ (36,35\% da área total). A partir do mês de abril observa-se uma redução nos valores de GPP para as áreas de caatinga e de agropecuária (ao norte). Essa redução é interrompida em novembro, com os primeiros registros de precipitação na região, que mesmo sendo abaixo do esperado para o ano de 2012, foi suficiente para elevar a assimilação de carbono nas áreas de caatinga do município, principalmente na porção oeste-noroeste do mesmo. Nestas, o carbono assimilado variou de 60 a $80 \mathrm{~g} \mathrm{C} / \mathrm{m}^{2}$, contudo nas áreas de caatinga com presença de agropecuária esteve abaixo de $20 \mathrm{~g} \mathrm{C} / \mathrm{m}^{2}$ nos últimos meses do ano.

No tocante à variação mensal do sequestro de carbono constatou-se que a variabilidade sazonal da precipitação exerceu forte influência no quantitativo de carbono sequestrado pela vegetação nativa. Sendo assim, no período chuvoso do ano de 2011, uma quantidade maior de carbono foi incorporada na biomassa vegetal, com destaque para o mês de janeiro, cuja concentração de valores esteve entre $100 \mathrm{e}$ $120 \mathrm{~g} \mathrm{C} / \mathrm{m}^{2}$ na região de caatinga preservada (Fig. 6). Em 

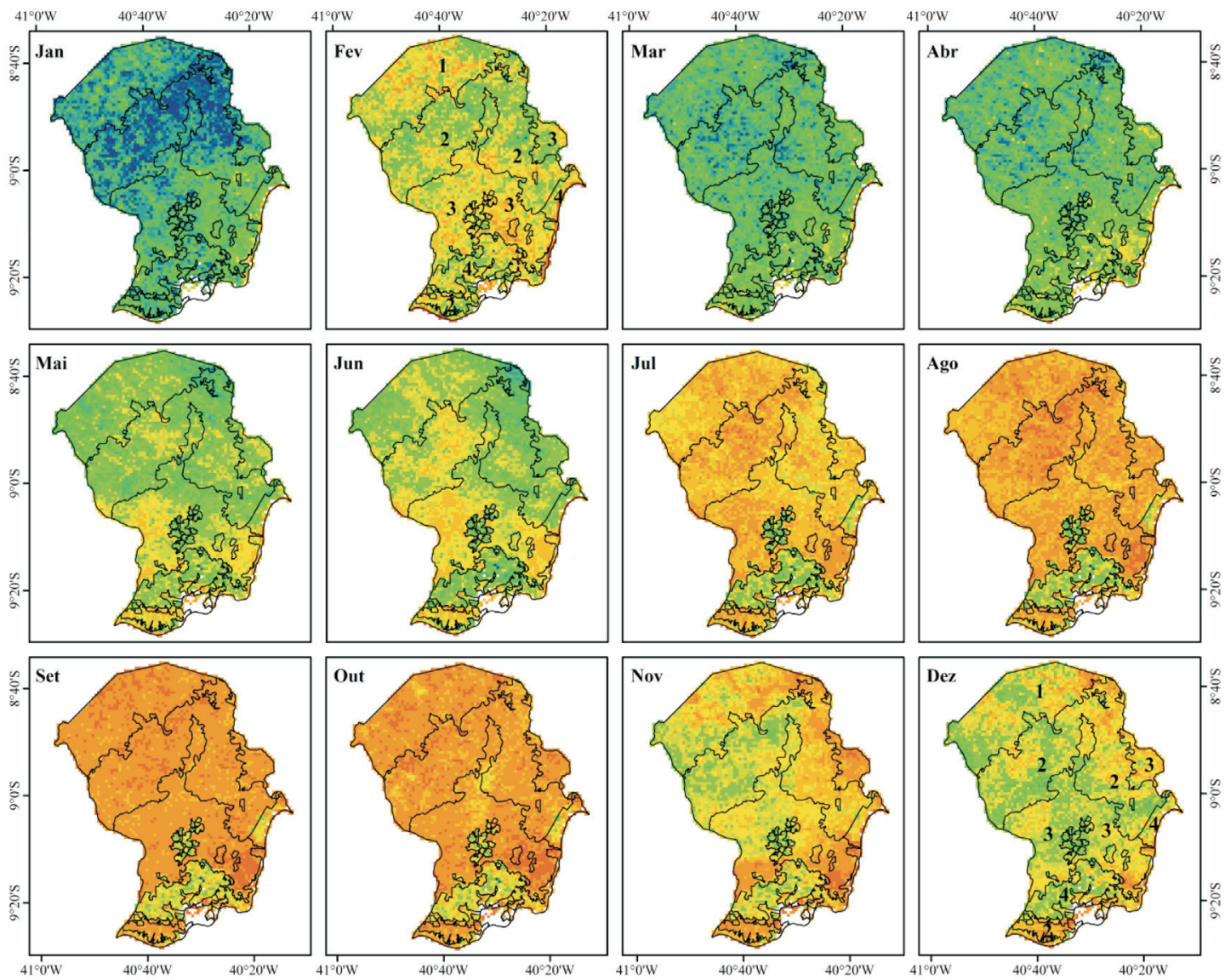

$\operatorname{LEGENDA} \operatorname{GPP}\left(\mathrm{g} \mathrm{C}^{\mathrm{m}} \mathrm{m}^{2}\right)$

\begin{tabular}{|c|c|c|c|}
\hline$<10$ & $30,0001-40$ & $60,0001-80$ & $120,0001-140$ \\
\hline $10,0001-20$ & $40,0001-50$ & $80,0001-100$ & $140,0001-160$ \\
\hline $20,0001-30$ & $500001-60$ & $1000001-120$ & \\
\hline
\end{tabular}

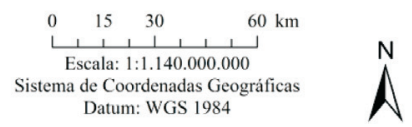

Figura 4 - Variação mensal da Produção Primária Bruta (GPP) do município de Petrolina, para o ano de 2011. Legenda: 1- Agropecuária com presença de caatinga arborizada; 2- Caatinga arborizada; 3- Caatinga arborizada com presença de agropecuária; 4- Agricultura irrigada.

fevereiro houve uma redução da $N P P$, com predomínio de valores entre 20 e $30 \mathrm{~g} \mathrm{C} / \mathrm{m}^{2}$ (37,2\% da área total). No início do período seco ainda é possível observar valores de $N P P$ de até $80 \mathrm{~g} \mathrm{C} / \mathrm{m}^{2}$, sobretudo ao norte-nordeste do município, correspondendo as regiões de caatinga preservada e agropecuária (com presença de caatinga). Quanto às áreas de agricultura irrigada, nota-se que a NPP também foi mais alta no período chuvoso, atingindo valores entre 80 e $100 \mathrm{~g} \mathrm{C} / \mathrm{m}^{2}$, entretanto na estação seca a redução não foi abrupta, quando comparada à registrada nas demais áreas do município. Neste período, verifica-se, ainda, NPP de até $70 \mathrm{~g} \mathrm{C} / \mathrm{m}^{2}$ em algumas localidades dos perímetros irrigados Nilo Coelho e Bebedouro (Fig. 6).

Em 2012 o sequestro de carbono foi menor ao longo de todo ano, quando comparado a 2011, em função do baixo índice pluviométrico. Em todos os meses de 2012, com exceção de fevereiro, o sequestro de carbono das áreas de caatinga e de agropecuária não ultrapassou $50 \mathrm{~g} \mathrm{C} / \mathrm{m}^{2}$ (Fig. 7). No mês de fevereiro é possível observar valores de $N P P$ entre 70 e $80 \mathrm{~g} \mathrm{C} / \mathrm{m}^{2}$ em algumas localidades das regiões de caatinga arborizada preservada e de agropecuária (com presença de caatinga) ao norte do município de Petrolina. Além disso, no início do período seco houve um ligeiro aumento da $N P P$ nas áreas de caatinga, o qual pode estar associado à ocorrência de chuvas esporádicas que, mesmo sendo em pequenas quantidades, são suficientes para elevar a atividade fotossintética e provocar, consequentemente, o rebrotamento de algumas folhas.

As Figs. 4, 5, 6 e 7 mostraram que o padrão de variação da assimilação total e do sequestro de carbono variou de acordo com o comportamento mensal da precipitação, e em cada mês houve diferenças, do ponto de vista espacial, na absorção de $\mathrm{CO}_{2}$ de acordo com o uso e cobertura da terra. Neste aspecto, as áreas localizadas a sudeste e sudoeste do município apresentaram um sequestro de carbono menor no início do período chuvoso (novembro e dezembro), em comparação com as áreas de caatinga mais preservadas. Além disso, com o término da estação chuvosa, houve uma redução mais rápida da assimilação de carbono nas áreas antropizadas. Tais áreas estão locali- 
zadas próximas ao perímetro irrigado Senador Nilo Coelho e da zona urbana no município, evidenciando, assim, a influência das atividades antrópicas no sequestro de carbono.
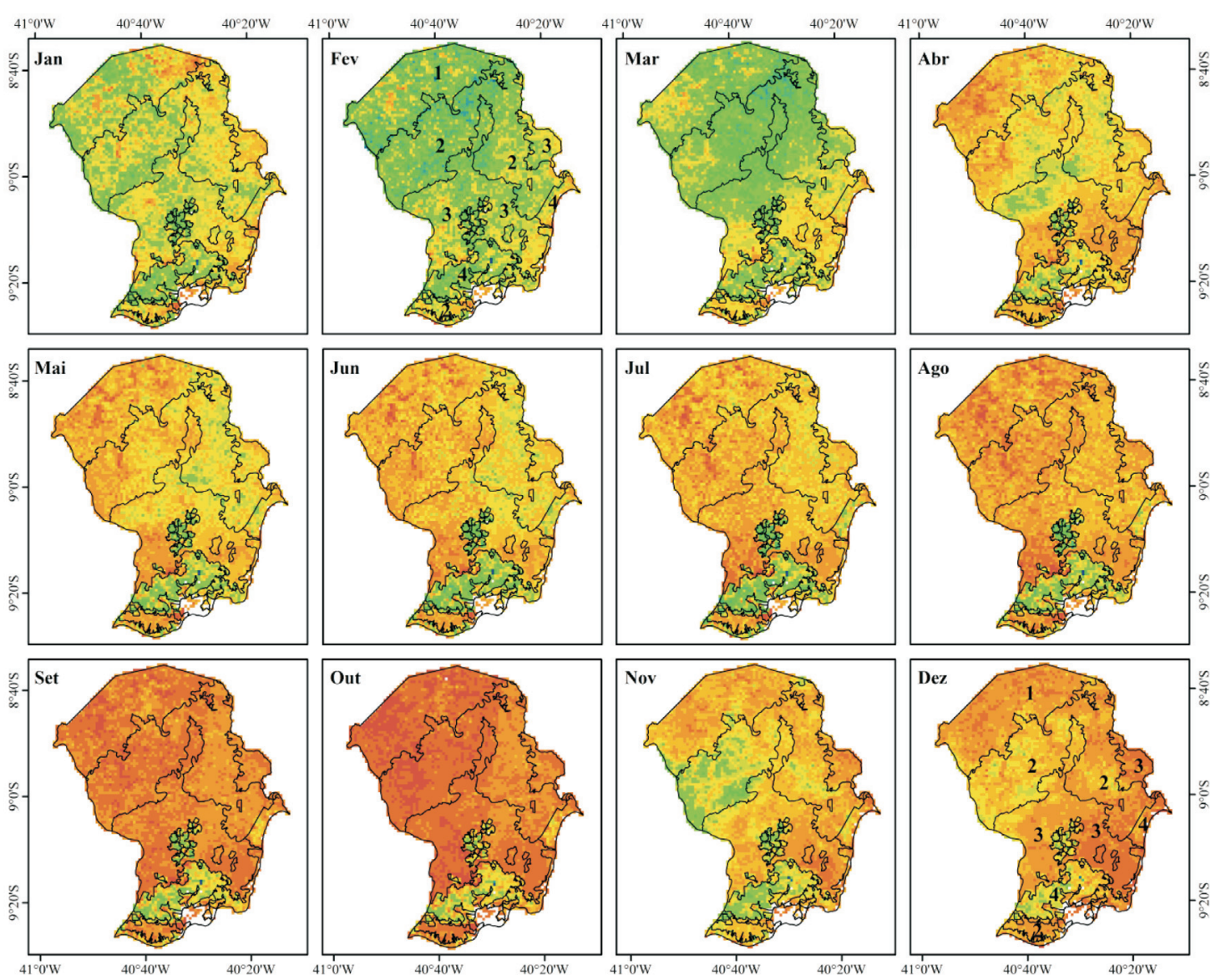

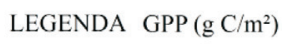

\begin{tabular}{|c|c|c|c|}
\hline$<10$ & $30,0001-40$ & $60,0001-80$ & $120,0001-140$ \\
\hline $001-20$ & $40,0001-50$ & $80,0001-100$ & $140,0001-160$ \\
\hline $20,0001-30$ & $50,0001-60$ & $100,0001-120$ & $>160$ \\
\hline
\end{tabular}

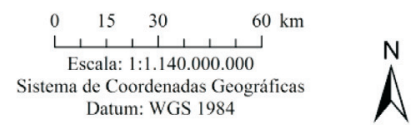

Figura 5 - Variação mensal da Produção Primária Bruta (GPP) do município de Petrolina, para o ano de 2012. Legenda: 1- Agropecuária com presença de caatinga arborizada; 2- Caatinga arborizada; 3- Caatinga arborizada com presença de agropecuária; 4- Agricultura irrigada.
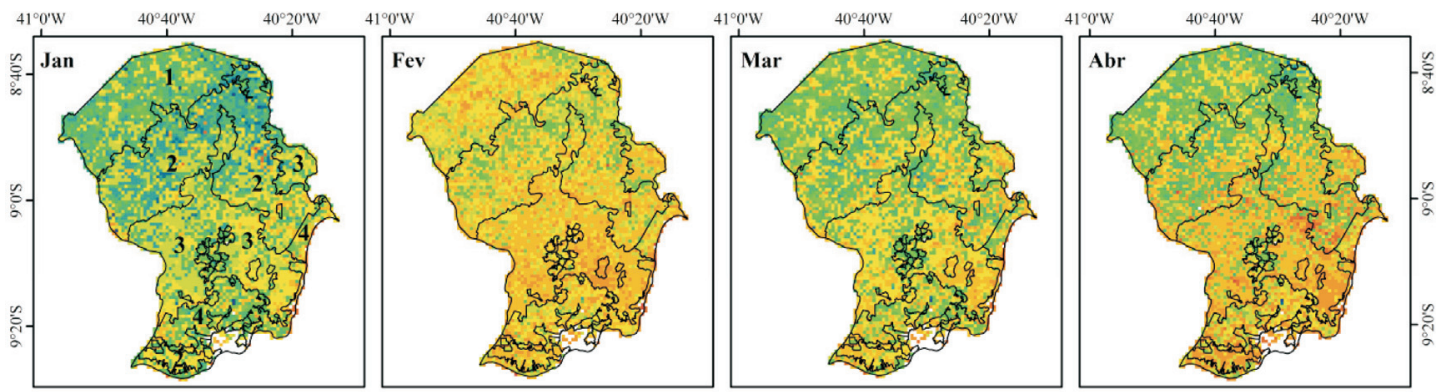

LEGENDA NPP $\left(\mathrm{g} \mathrm{C}^{2} \mathrm{~m}^{2}\right)$
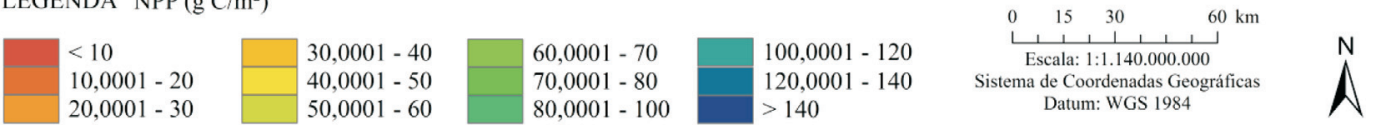

Figura 6 - Variação mensal da Produção Primária Líquida (NPP) do município de Petrolina, para o ano de 2011. Legenda: 1- Agropecuária com presença de caatinga arborizada; 2- Caatinga arborizada; 3- Caatinga arborizada com presença de agropecuária; 4- Agricultura irrigada. 

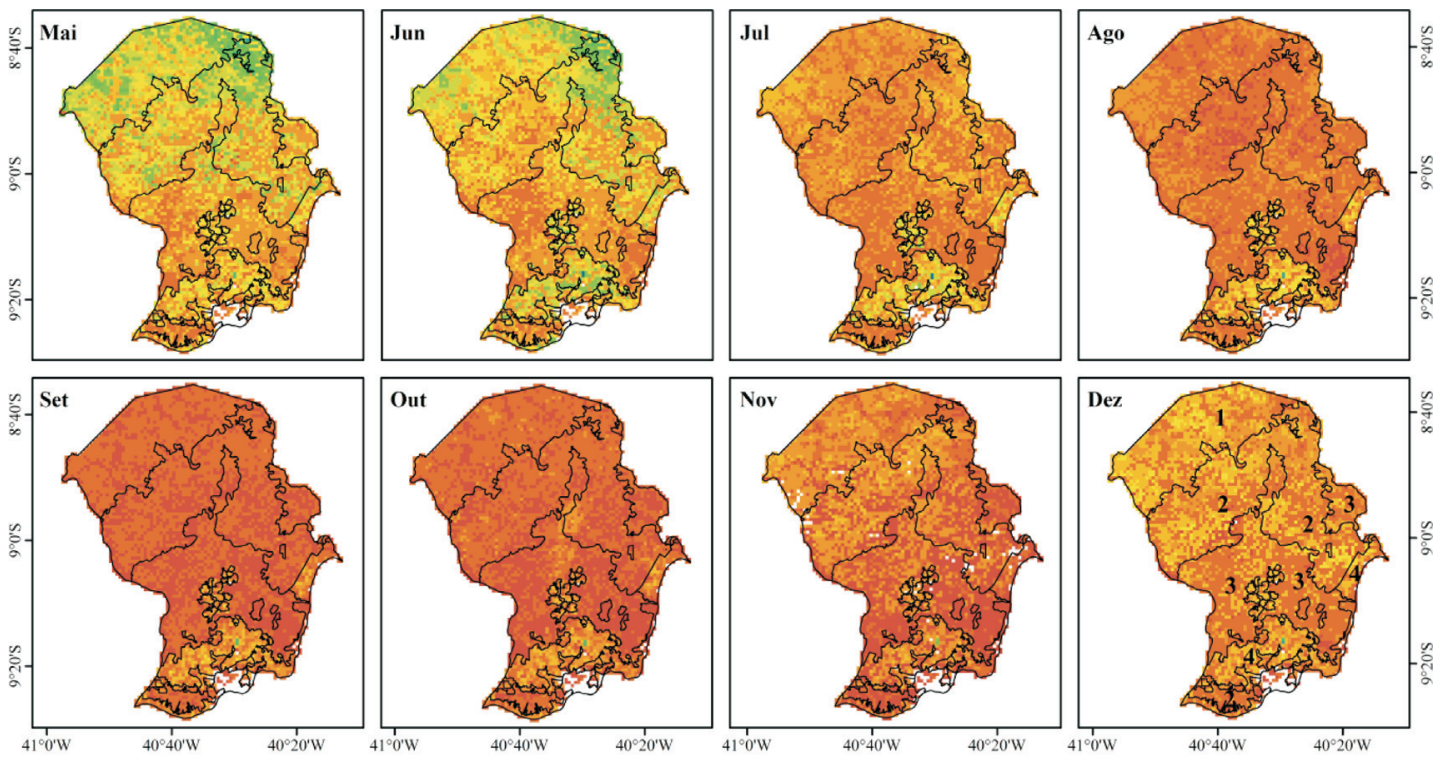

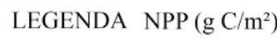
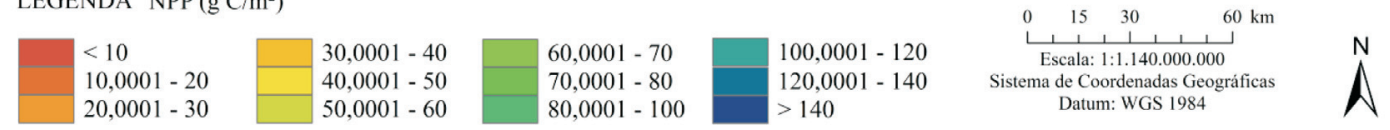

Figura 6 - cont.
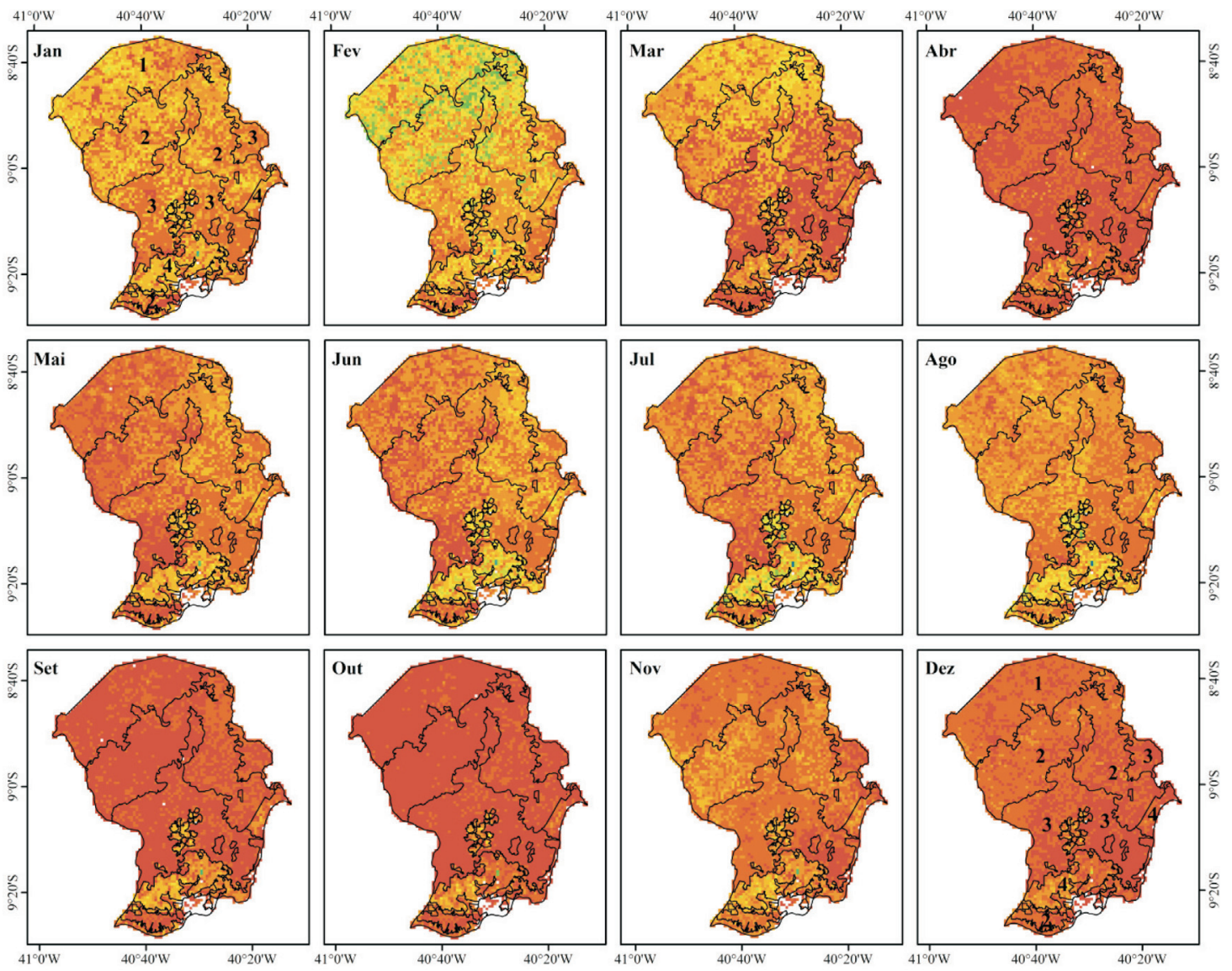

LEGENDA NPP $\left(\mathrm{g} \mathrm{C}^{\mathrm{m}} \mathrm{m}^{2}\right)$

\begin{tabular}{l|l|}
$<10$ & $30,0001-40$ \\
$10,0001-20$ & $40,0001-50$ \\
$20,0001-30$ & $50,0001-60$
\end{tabular}
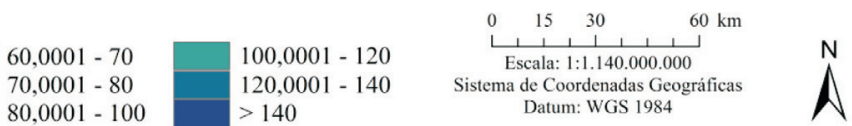

Figura 7 - Variação mensal da Produção Primária Líquida (NPP) do município de Petrolina, para o ano de 2012. Legenda: 1- Agropecuária com presença de caatinga arborizada; 2- Caatinga arborizada; 3- Caatinga arborizada com presença de agropecuária; 4- Agricultura irrigada. 
Estudos mostram que alterações induzidas por ações antrópicas podem provocar mudanças na estrutura da vegetação, na fitofisionomia e diversidade de espécies da caatinga (Amorim et al., 2005; Holanda et al., 2015). Sendo assim, as mudanças na estrutura da vegetação (altura, diâmetro, densidade, dentre outros) influenciam no índice de área foliar e na fração da radiação fotossinteticamente ativa absorvida, a qual, segundo Coops et al. (2007), é uma variável fundamental para explicar a variação da assimilação de carbono.

\subsection{Variação anual do sequestro de carbono para os anos de 2011 e 2012}

A Fig. 8 traz a produção primária bruta acumulada das diferentes coberturas vegetais presentes no município de Petrolina, para os anos de 2011 e 2012. Nota-se, então, que a $G P P$ anual variou de 113 a $1152 \mathrm{~g} \mathrm{C} / \mathrm{m}^{2}$ em 2011 e de 92 a 1280 g C/m² em 2012. Em 2011, as áreas de caatinga preservada juntamente com a agricultura irrigada apresentaram os maiores valores de $G P P\left(>900 \mathrm{~g} \mathrm{C} / \mathrm{m}^{2}\right)$. Neste ano, a classe predominante foi a com valores entre $600 \mathrm{e}$ $700 \mathrm{~g} \mathrm{C} / \mathrm{m}^{2}$ (32,8\%) e entre 700 e $800 \mathrm{~g} \mathrm{C} / \mathrm{m}^{2}$ (24,26\%). Por outro lado, em 2012 a GPP das áreas de caatinga foi, em geral, mais baixa do que a registrada no ano anterior, em virtude das chuvas abaixo da média histórica. Com isso, nota-se que as áreas irrigadas se destacam dentre as demais, atingindo valores acima de $900 \mathrm{~g} \mathrm{C} / \mathrm{m}^{2}$, e as áreas de caatinga (centro-norte do município) apresentaram GPP entre 500 e $600 \mathrm{~g} \mathrm{C} / \mathrm{m}^{2}$ com algumas áreas chegando a até $700 \mathrm{~g} \mathrm{C} / \mathrm{m}^{2}$ (Fig. 8). As classes predominantes registraram
$G P P$ entre 400 e $500 \mathrm{~g} \mathrm{C} / \mathrm{m}^{2}(33,56 \%)$ e 300 e $400 \mathrm{~g} \mathrm{C} / \mathrm{m}^{2}$ $(27,4 \%)$.

Com o objetivo de visualizar com mais detalhe a variação da GPP nos diferentes tipos de uso e cobertura da terra, foram elaborados quatro transectos ao longo do município de Petrolina, no sentido oeste-leste. Deste modo, o transecto 1 (Fig. 9) está localizado ao norte do município de Petrolina e tem início em uma área de agricultura de sequeiro com presença de caatinga, onde a GPP variou de aproximadamente 550 a $790 \mathrm{~g} \mathrm{C} / \mathrm{m}^{2}$ em 2011 e de 200 a $780 \mathrm{~g} \mathrm{C} / \mathrm{m}^{2}$ em 2012. A partir dos $30 \mathrm{~km}$ de distância, os valores correspondem à caatinga preservada, a qual apresentou $G P P$ superior do que a área de sequeiro (710 a $\left.990 \mathrm{~g} \mathrm{C} / \mathrm{m}^{2}\right)$.

$\mathrm{O}$ transecto 2 se inicia na área de agricultura de sequeiro com presença de caatinga, onde podemos verificar que os valores de GPP anual atingem o máximo de aproximadamente $940 \mathrm{~g} \mathrm{C} / \mathrm{m}^{2}$ em 2011 (Fig. 10a). Logo após, na área de caatinga mais preservada, os valores de GPP oscilam entre 650 a $920 \mathrm{~g} \mathrm{C} / \mathrm{m}^{2}$ em 2011 e de 350 a $600 \mathrm{~g} \mathrm{C} / \mathrm{m}^{2}$ em 2012 (Fig. 10b). Nos 10 quilômetros finais do transecto, os valores são mais baixos em ambos os anos, pois este trecho corresponde à área de caatinga com presença de agropecuária.

O transecto 3 está localizado na porção central do município de Petrolina e seus $10 \mathrm{~km}$ iniciais estão inseridos em área de caatinga preservada, com valores anuais de GPP que variam de 550 a 859 g C/m² em 2011 e 517 a $670 \mathrm{~g} \mathrm{C} / \mathrm{m}^{2}$ em 2012. Além disso, percebe-se que não variou muito de uma área para outra, tendo destaque o trecho entre os 16 e $24 \mathrm{~km}$, localizado em área de caatinga

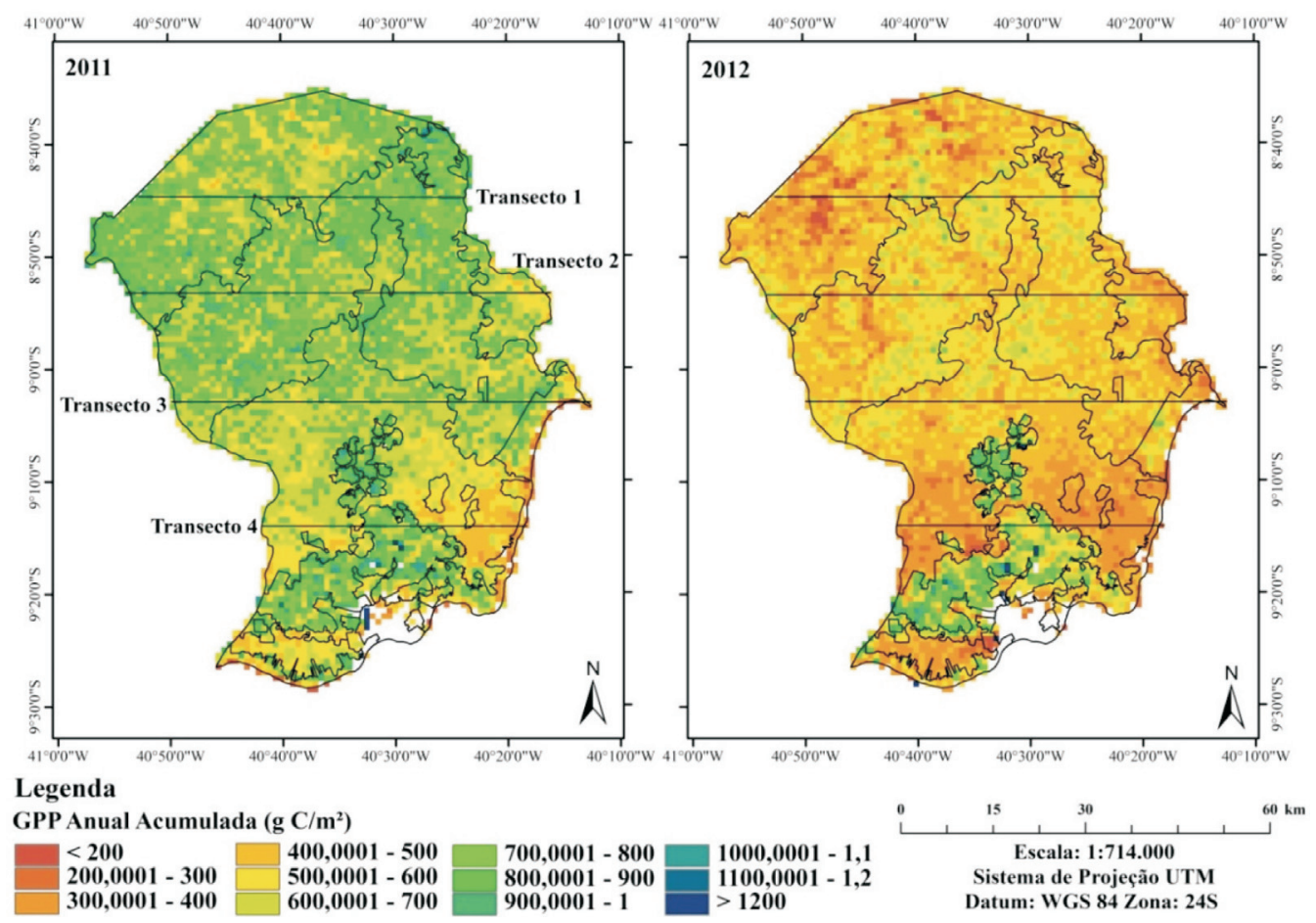

Figura 8 - Variação anual da produção primária bruta do município de Petrolina, para o ano de 2011 e 2012. 


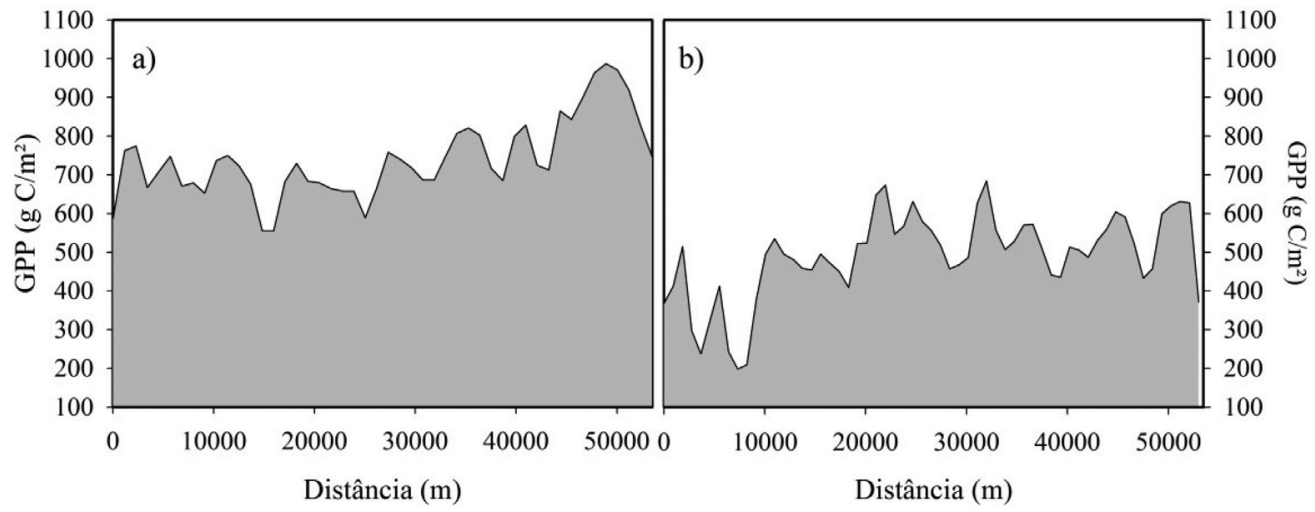

Figura 9 - Perfil 1 (transecto) referente à variação espacial da GPP anual dos anos de 2011 (a) e 2012 (b).
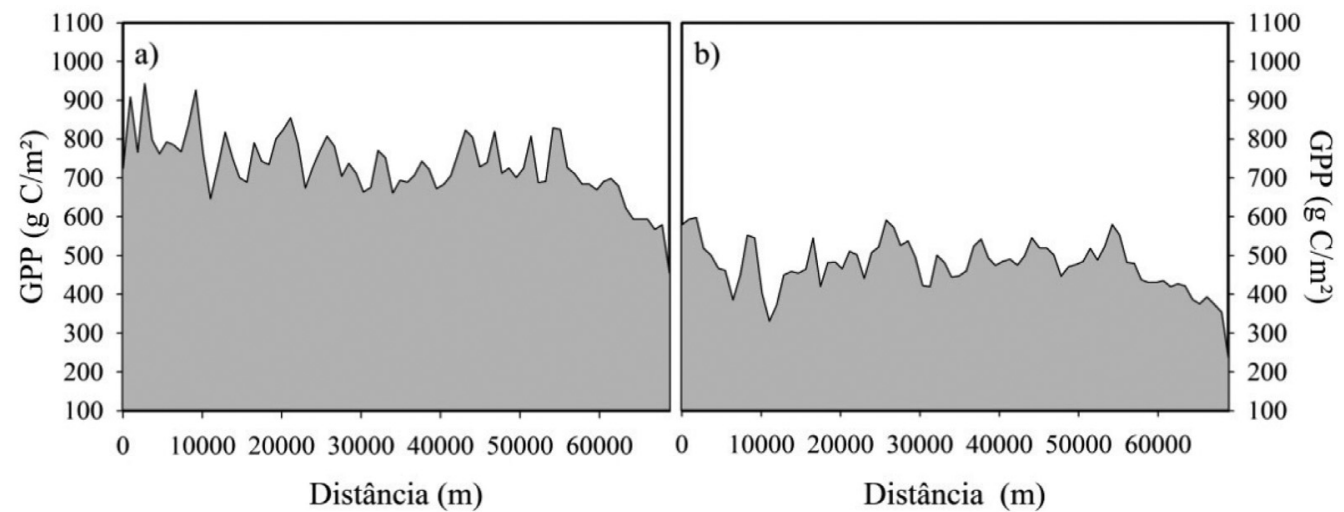

Figura 10 - Perfil 2 (transecto) referente à variação espacial da GPP anual dos anos de 2011 (a) e 2012 (b).

antropizada, que apresentou $G P P$ inferior a $620 \mathrm{~g} \mathrm{C} / \mathrm{m}^{2}$, como pode ser observado na Fig. 11.

O transecto 4 está localizado ao sul do município de Petrolina e mostra a variação da $G P P$ tendo como ponto inicial a área de caatinga com presença de agropecuária. Assim como nos demais, a GPP anual foi maior em 2011, em todo o transecto. Além disso, a caatinga com presença de agropecuária apresentou, em 2011, valores entre 520 e $710 \mathrm{~g} \mathrm{C} / \mathrm{m}^{2}$ na porção oeste e 380 a $630 \mathrm{~g} \mathrm{C} / \mathrm{m}^{2}$ a leste (Fig. 12a). Na metade do transecto (entre aproximadamente
15 e 26 km de distância), a GPP anual foi mais elevada devido à presença da agricultura irrigada, atingindo valores de aproximadamente $940 \mathrm{~g} \mathrm{C} / \mathrm{m}^{2}$ (2011) e $740 \mathrm{~g} \mathrm{C} / \mathrm{m}^{2}$ (2012).

No que se refere ao sequestro de carbono $(N P P)$, nota-se por meio da Fig. 13 que a $N P P$ anual foi maior nas áreas de agricultura irrigada, de caatinga preservada e agricultura de sequeiro (ao norte). Em 2011, houve a predominância de $N P P$ entre 250 e $300 \mathrm{~g} \mathrm{C} / \mathrm{m}^{2}(30,72 \%)$, e as áreas de caatinga mais preservadas apresentaram $N P P$ variando,
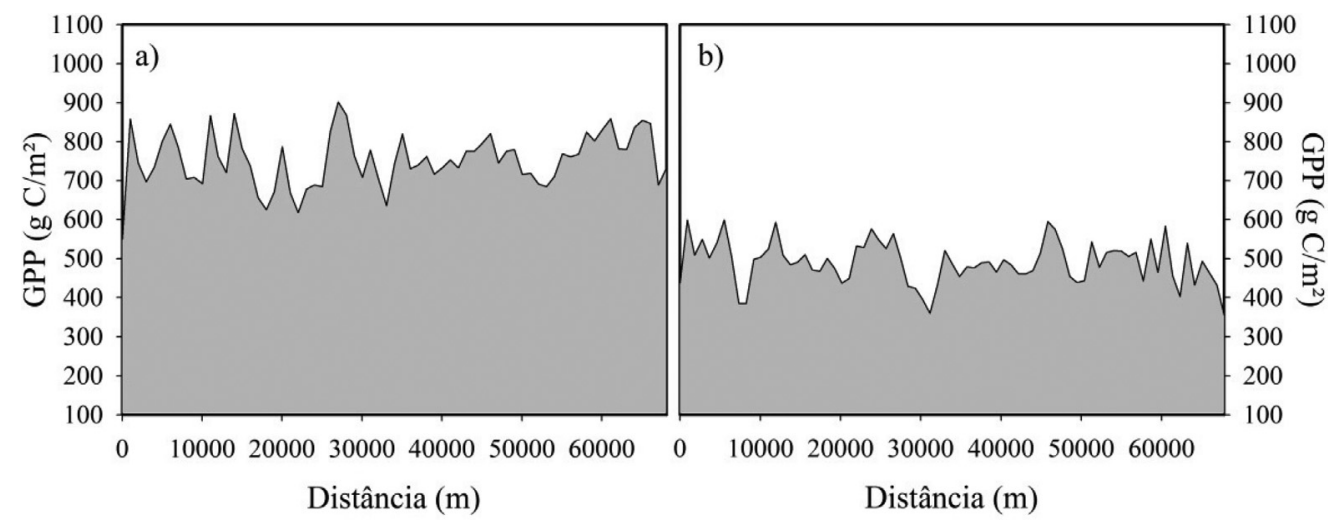

Figura 11 - Perfil 3 (transecto) referente à variação espacial da GPP anual dos anos de 2011 (a) e 2012 (b). 

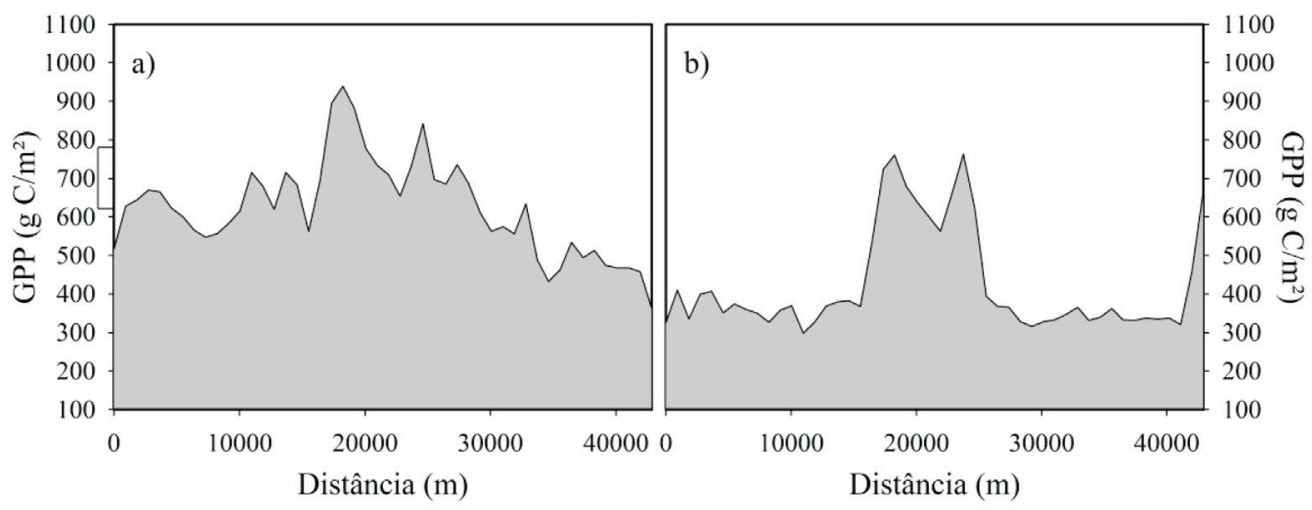

Figura 12 - Perfil 4 (transecto) referente à variação espacial da GPP anual dos anos de 2011 (a) e 2012 (b).

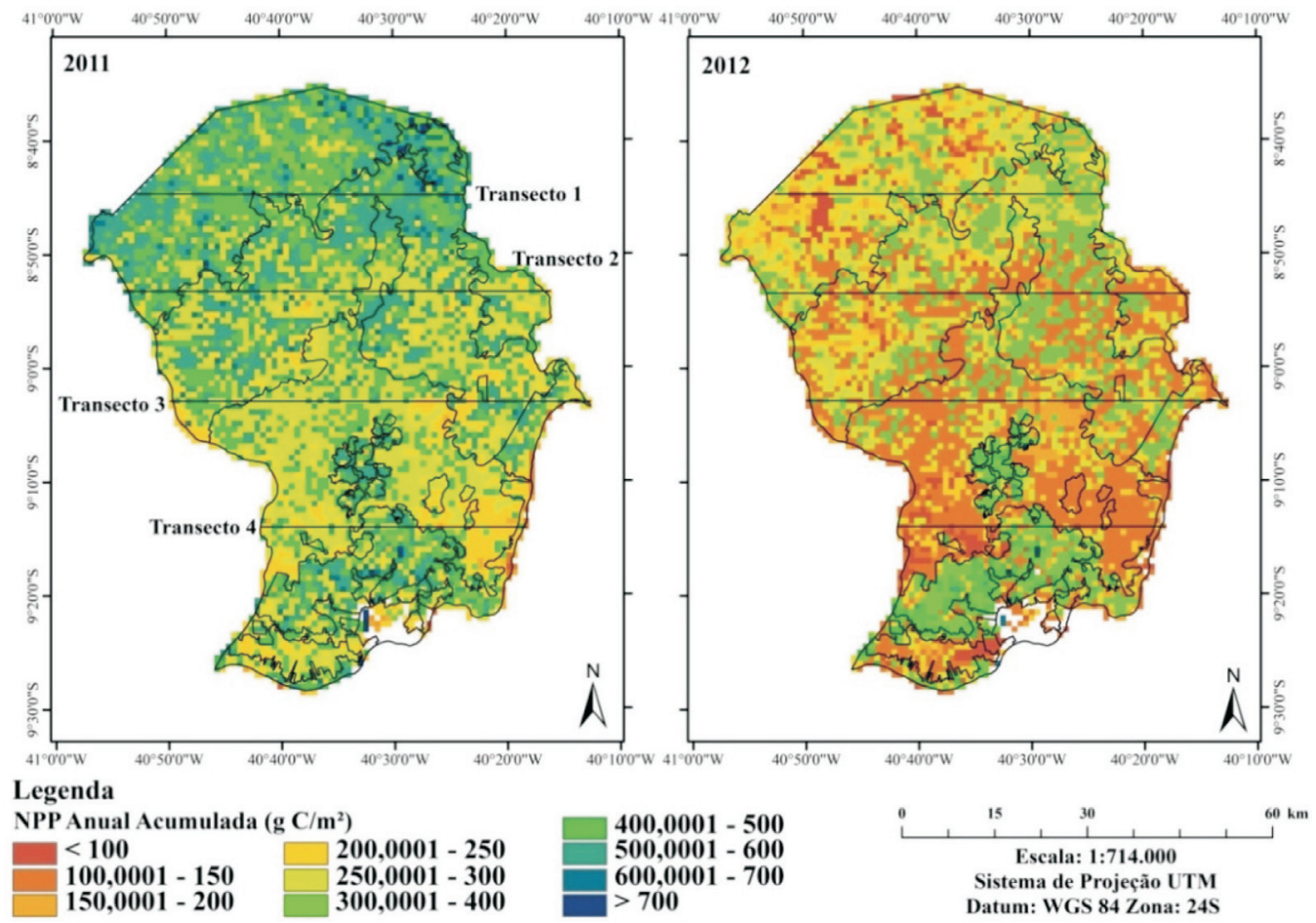

Figura 13 - Variação anual da produção primária líquida do município de Petrolina, para os anos de 2011 e 2012.

em geral, de 500 a $600 \mathrm{~g} \mathrm{C} / \mathrm{m}^{2}$, enquanto que a caatinga com presença de agropecuária apresentou os menores valores (200 a $250 \mathrm{~g} \mathrm{C} / \mathrm{m}^{2}$ ), se destacando nesta categoria a porção sudeste do município. Por outro lado, assim como a assimilação total de carbono (GPP), o sequestro de carbono também foi mais baixo durante o ano de 2012, com destaque para a agricultura irrigada e algumas áreas de caatinga preservada, as quais foram responsáveis por sequestrar mais de $400 \mathrm{~g} \mathrm{C} / \mathrm{m}^{2}$ ao ano.

Durante o ano de 2011, quando as chuvas estiveram próximo à média histórica, a $N P P$ acumulada se aproximou dos valores encontrados por Grace (2005), que com base em estudo de outros autores, estabeleceu que as Florestas Temperadas sequestram $775 \mathrm{~g} \mathrm{C} \mathrm{m}^{2} /$ ano, enquanto a Flo- resta Boreal $190 \mathrm{~g} \mathrm{C} \mathrm{m}^{2} /$ ano e a Savana Tropical $540 \mathrm{~g} \mathrm{C} \mathrm{m}^{2} /$ ano.

Eisfelder et al. (2014) analisaram a NPP para o Cazaquistão, entre os anos de 2003 e 2011, em áreas de clima árido e semiárido (precipitação de $100 \mathrm{a} 400 \mathrm{~mm}$ ), e obtiveram valores médios de $N P P$ de $338 \mathrm{~g} \mathrm{C} / \mathrm{m}^{2}$ para a agricultura irrigada, $264 \mathrm{~g} \mathrm{C} / \mathrm{m}^{2}$ para áreas florestadas e $120 \mathrm{~g} \mathrm{C} / \mathrm{m}^{2}$ para vegetação esparsa. Sendo assim, os valores encontrados para o referido trabalho se aproximam daqueles obtidos para o ano de 2012 no município de Petrolina, e eventuais diferenças podem estar relacionadas com o método em que a $N P P$ foi estimada e os aspectos climáticos de cada área.

Outros estudos em ambientes semelhantes também relatam quantitativos de sequestro de carbono comparáveis 
com os obtidos para a caatinga. Zhang et al. (2014), por exemplo, analisaram a variabilidade espaço-temporal da $N P P$ associada a GPP para a bacia do rio Yang Tze, na China, de 2000 a 2009, e encontraram GPP e NPP variando de 530 a $958 \mathrm{~g} \mathrm{C} \mathrm{m}^{2} /$ ano e 272 a $489 \mathrm{~g} \mathrm{C} \mathrm{m}^{2} /$ ano, respectivamente, em áreas de savanas arbóreas. Yu et al. (2009) estimaram valores médios anuais de $N P P$ de $144 \mathrm{~g} \mathrm{C} / \mathrm{m}^{2}$ para vegetação arbustiva aberta, $228 \mathrm{~g} \mathrm{C} / \mathrm{m}^{2}$ para pastagens, e $266 \mathrm{~g} \mathrm{C} / \mathrm{m}^{2}$ para vegetação arbustiva fechada inseridas na Ásia oriental.

A Fig. 14 traz a variação da $N P P$ anual ao longo de um perfil de transecto, nos anos de 2011 (Fig. 14a) e 2012 (Fig. 14b). Sendo assim, é possível observar que, em geral, a $N P P$ for maior no ano de 2011, com destaque para o ponto localizado a $50 \mathrm{~km}$ de distância (em área de caatinga preservada), cuja $N P P$ foi superior a $600 \mathrm{~g} \mathrm{C} / \mathrm{m}^{2}$. Os valores mais baixos $\left(<330 \mathrm{~g} \mathrm{C} / \mathrm{m}^{2}\right)$, em 2011, foram encontrados na área de agricultura de sequeiro (entre aproximadamente 2 e $9 \mathrm{~km})$.

O transecto 2 se inicia em área de agricultura de sequeiro com presença de caatinga arborizada e, nesta área nota-se que a NPP atingiu um pico de aproximadamente $635 \mathrm{~g} \mathrm{C} / \mathrm{m}^{2}$ no ano de 2011 (Fig. 15a). Em seguida tem-se a área de caatinga arborizada sem presença de agropecuária, cujos valores de $N P P$ variaram entre 255 a $257 \mathrm{~g} \mathrm{C} / \mathrm{m}^{2}$. Enquanto isso, no final do transecto, onde se localiza a área de caatinga com presença de agropecuária, a $N P P$ apresentou em média valores inferiores àqueles registrados nas demais áreas. No ano de 2012, a NPP seguiu o mesmo padrão do ano anterior, porém com valores mais baixos. Neste ano, a o sequestro de carbono variou de 103 a $325 \mathrm{~g} \mathrm{C} / \mathrm{m}^{2}$, apresentado valores mais elevados na área de agricultura de sequeiro e de caatinga preservada (Fig. 15b).

O início do Perfil/Transecto 3 está inserido em área de caatinga preservada, onde são observados valores de $N P P$ acima de $500 \mathrm{~g} \mathrm{C} / \mathrm{m}^{2}$ em 2011 e de $250 \mathrm{~g} \mathrm{C} / \mathrm{m}^{2}$ em 2012 (Figs. 16a-16b). Na região de caatinga com presença de agropecuária (antropizada), contudo, se verifica uma redução do sequestro de carbono anual, com valores inferiores a $300 \mathrm{~g} \mathrm{C} / \mathrm{m}^{2}$ e $150 \mathrm{~g} \mathrm{C} / \mathrm{m}^{2}$, respectivamente, principalmente entre 14 e $22 \mathrm{~km}$ de distância. No final no Perfil 3, a partir de $45 \mathrm{~km}$ de distância, o sequestro de carbono foi, em geral, mais elevado, com valores atingindo $580 \mathrm{~g} \mathrm{C} / \mathrm{m}^{2}$ (2011) e $405 \mathrm{~g} \mathrm{C} / \mathrm{m}^{2}$ (2012). Estas áreas estão ocupadas pela caatinga preservada e a agricultura irrigada, sendo esta referente ao Perímetro irrigado de Bebedouro.

Analisando a Fig. 17 observa-se que os valores da $N P P$ anual foram mais elevados entre as distâncias de $18 \mathrm{e}$

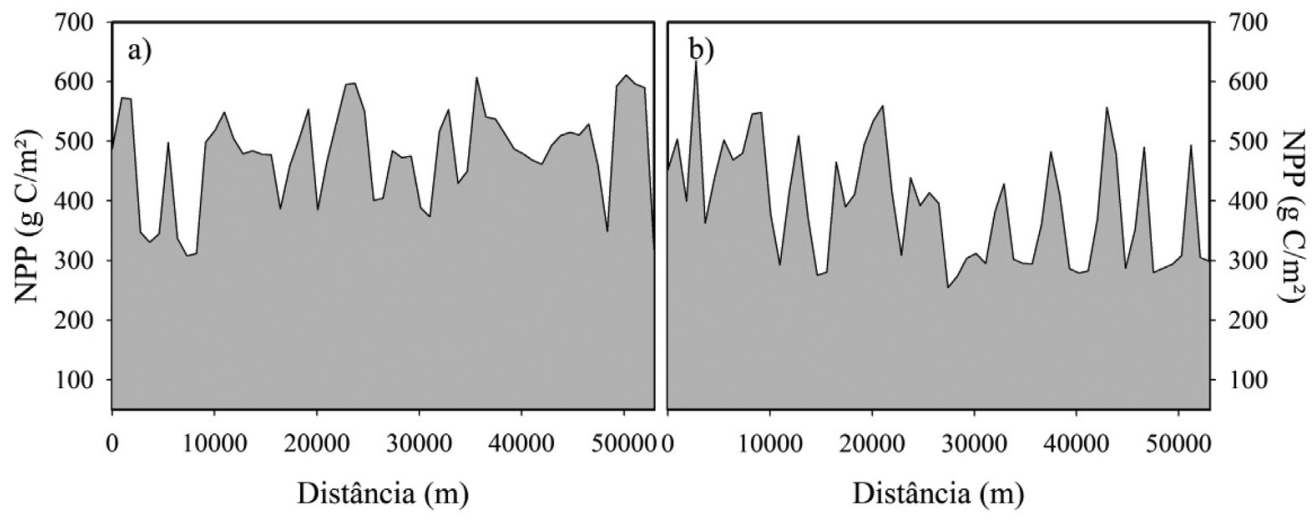

Figura 14 - Perfil 1 (transecto) referente à variação espacial da NPP anual dos anos de 2011 (a) e 2012 (b).

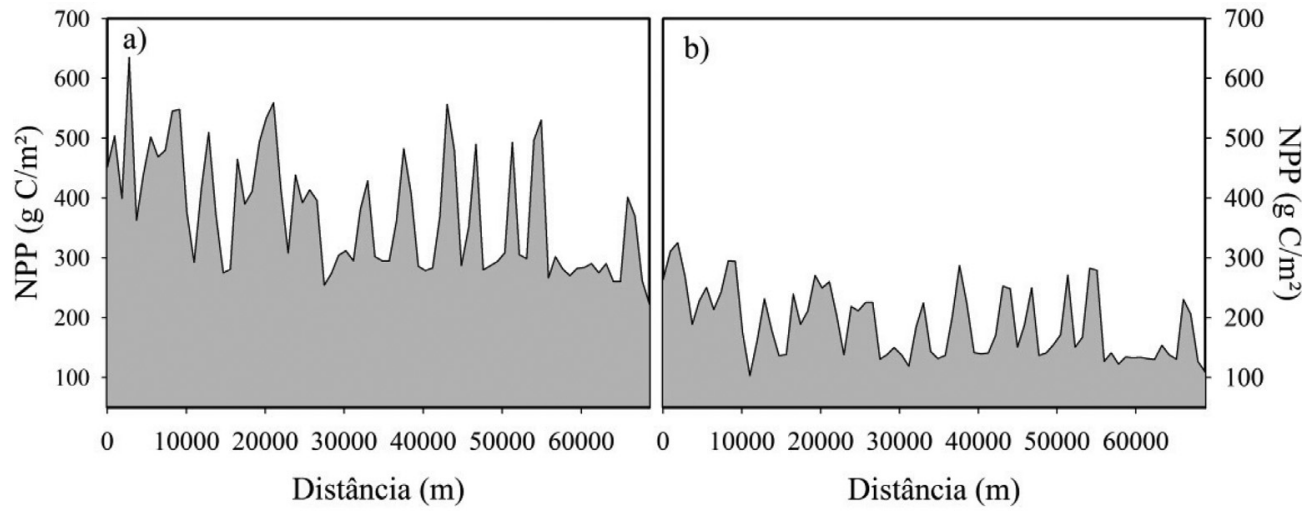

Figura 15 - Perfil 2 (transecto) referente à variação espacial da NPP anual dos anos de 2011 (a) e 2012 (b). 


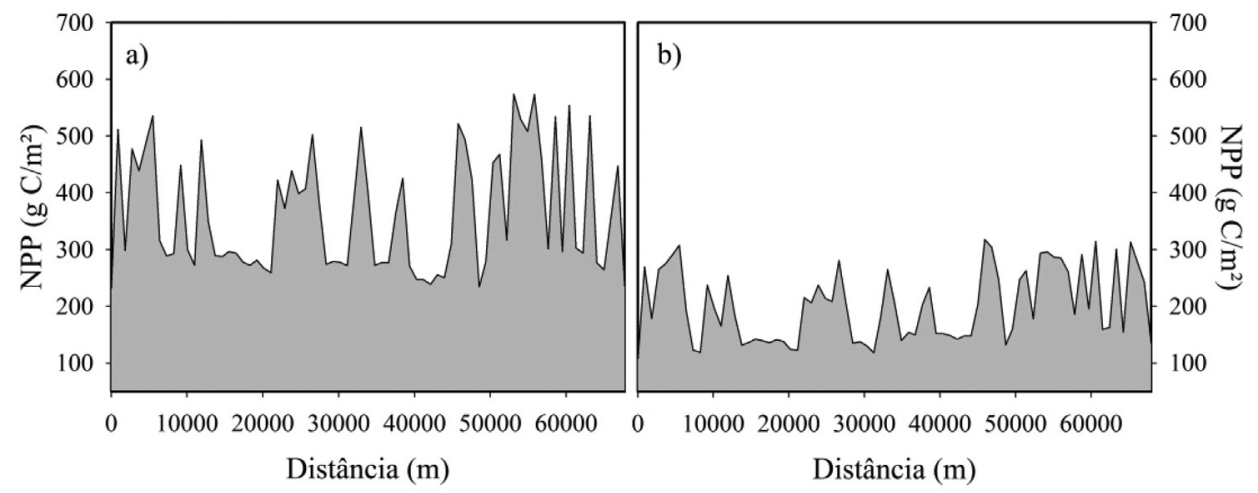

Figura 16 - Perfil 3 (transecto) referente à variação espacial da NPP anual dos anos de 2011 (a) e 2012 (b).
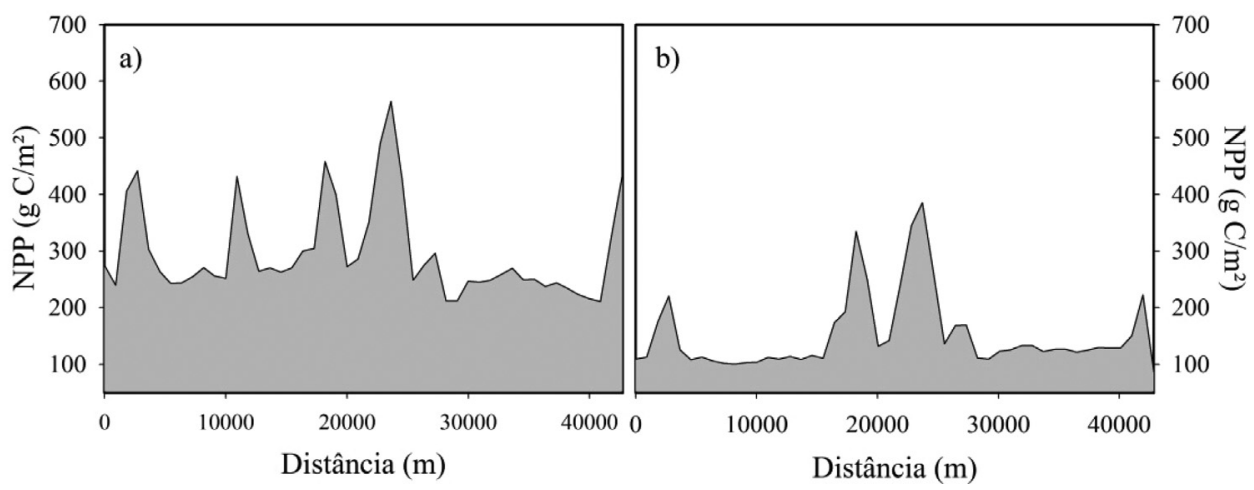

Figura 17 - Perfil 4 (transecto) referente à variação espacial da NPP anual dos anos de 2011 (a) e 2012 (b).

$25 \mathrm{~km}$, os quais correspondem às terras destinadas a agricultura irrigada. Sendo assim, a NPP nesta apresentou valor de $565 \mathrm{~g} \mathrm{C} / \mathrm{m}^{2}$ em 2011 e $386 \mathrm{~g} \mathrm{C} / \mathrm{m}^{2}$ em 2012. Em contrapartida, as demais áreas abrangidas pelo Perfil 4 apresentaram $N P P$ mais baixas, já que estas correspondem à caatinga arborizada com presença de agropecuária.

A análise dos transectos mostra que, no geral, a assimilação total $(G P P)$ e o sequestro de carbono $(N P P)$ foram superiores nas áreas de caatinga mais preservadas, quando comparadas com as áreas onde há presença de agropecuária. Conforme Kauffman et al. (2009) e Don et al. (2011) os estoques de $\mathrm{C}$ na vegetação e no solo dependem muito das formas de manejo da área. Áreas cobertas com vegetação nativa de caatinga arbustiva e arbórea têm um estoque de biomassa vegetal maior que o de áreas cobertas com vegetação herbácea, como as pastagens abertas, e maior que as áreas plantadas com culturas de ciclo curto (Sampaio e Costa, 2011).

Evitar o desmatamento pode reduzir a liberação de carbono para a atmosfera e, ainda, fornecer habitat para espécies animais e vegetais, pasto para o gado e madeira e lenha para o uso sustentável da população. Além disso, a manutenção das áreas florestadas pode ter um efeito favorável sobre as condições meteorológicas e padrões climáticos (Liu et al., 2004). Contudo, a pressão antrópica sobre as áreas de caatinga vem aumentando nos últimos anos, sobretudo pelo crescimento populacional, expansão agrícola, e exploração para produção de carvão e lenha. Campello (2008) aponta que o uso da vegetação nativa para a produção de lenha e carvão vegetal constitui $30 \%$ da matriz energética local. Portanto, a utilização da caatinga como fonte energética juntamente com a conversão do uso da terra visando a produção agrícola são identificadas como as maiores ameaças para a fragmentação das áreas naturais (Giongo et al., 2011), refletindo, assim, no sequestro e estoque de carbono.

\section{Conclusões}

Os resultados mostraram que, no que se refere à variação espaço-temporal do sequestro de carbono, este foi maior no período chuvoso e, sobretudo, nas áreas de caatinga preservadas, com exceção da agricultura irrigada. Sendo assim, as áreas com alguma influência de atividades antrópicas apresentaram assimilação total e sequestro de carbono menor, pois a antropização pode provocar a mudança na composição e fisionomia da vegetação de caatinga, reduzindo os estratos vegetacionais e, consequentemente, o índice de área foliar e a fração da radiação fotossinteticamente ativa absorvida.

Sendo assim, são necessárias medidas e elaboração de instrumentos políticos que visem à preservação dos 
remanescentes de caatinga e a recuperação das áreas degradadas no município de Petrolina, como forma de contribuir para a mitigação do aquecimento global, possibilitando, então, o cumprimento das metas da Política Estadual de Enfrentamento as Mudanças Climáticas. A preservação dos remanescentes de caatinga pode ser feita mediante o manejo florestal controlado, o estabelecimento de sistemas agroflorestais, dentre outros, como forma de beneficiar as comunidades locais que dependem diretamente dos recursos da caatinga. Com isso, ao mesmo tempo se atingiria a redução do desmatamento, a geração de renda e o aumento do sequestro e estoques de carbono.

\section{Agradecimentos}

A Fundação de Amparo à Ciência e Tecnologia do Estado de Pernambuco (FACEPE) pela bolsa de mestrado concedida ao primeiro autor. A CAPES pela bolsa de doutorado concedida ao último autor. Ao Conselho Nacional de Desenvolvimento Científico e Tecnológico- CNPq pela bolsa de pesquisa a segunda e quarta autora. E, por fim, a EMBRAPA Semiárido pela disponibilização dos dados pluviométricos.

\section{Referências}

ALVES, J.M.B.; DINIZ, M.C.S. Um estudo preliminar de possíveis efeitos de mudanças climáticas no Nordeste do Brasil. Revista Brasileira de Geografia Física, Recife, v. 2, n. 2, p. 11-18, 2009.

AMORIM, I.L.B.; SAMPAIO, E.V.S.; ARAÚJO, E.L. Flora e estrutura da vegetação arbustivo-arbórea de uma área de caatinga do Seridó, RN, Brasil. Acta Botânica Brasílica, v. 19 , n. 3, p. 615-623, 2005.

ANDRADE, M.C. A terra e o homem no Nordeste: Contribuições ao estudo da questão agrária no Nordeste. 7. ed. São Paulo: Cortez, 2005.

ANGELOTTI, F.; FERNANDES JÚNIOR, P.I..; SÁ, I.B. de. Mudanças climáticas no Semiárido brasileiro: medidas de mitigação e adaptação. Revista Brasileira de Geografia Física, Recife, v. 4, n. 6, p. 1097-1111, 2011.

BARROS, J.D.S. Mudanças climáticas, degradação ambiental e desertificação no semiárido. Polêm!ca, Rio de Janeiro, v. 10, n. 3, p. 476-483, 2011.

BRASIL. Lei $\mathrm{n}^{\circ} 12.187$, de 29 de dezembro de 2009. Institui a Política Nacional sobre Mudança do Clima - PNMC e dá outras providências. Diário oficial da União, Poder Executivo, Brasília, DF, 30 de dezembro de 2009, Edição extra.

CAMPELLO, B.F. O uso da energia de biomassa no bioma Caatinga. In: SEMANA DO MEIO AMBIENTE, 5, Recife. Mudanças climáticas e o Nordeste brasileiro. Recife: Fundação Joaquim Nabuco, 2008. 1 CD-ROM.

CARVALHO, J.L.N.; AVANZI, J.C.; SILVA, M.L.N.; MELLO, C.R.; CERRI, C.E.P. Potencial de sequestro de carbono em diferentes biomas do Brasil. Revista Brasileira de Ciência do Solo, Viçosa, v. 34, n. 2, p. 277-289, 2010.

CONSELHO NACIONAL DA RESERVA DA BIOSFERA DA CAATINGA (CNRBC). Cenários para o Bioma Caatinga. Recife: SECTMA, 2004. 283 p.
COOPS, N.; BLACK, T.A.; JASSAL, R.S.; TROFYMOW, J.A.; MORGENSTERN, K. Comparison of MODIS, eddy covariance determined and physiologically modelled gross primary production (GPP) in a Douglas-fir forest stand. Remote Sensing of Environment, New York, v. 107, n. 3, p. 385-401, 2007.

DON, A.; SCHUMACHER, J.; FREIBAUER, A. Impact of tropical land-use change on soil organic carbon stocks - a metaanalysis. Global Change Biology, Oxford, v. 17, n. 4, p. 1658-1670, 2011.

EISFELDER, C.; KLEIN, I.; NIKLAUS, M., KUENZER, C. Net primary productivity in Kazakhstan, its spatio-temporal patterns and relation to meteorological variables. Journal of Arid Environments, London, v. 103, p. 17-30, 2014.

GALVÍNCIO, J.D.; NAUE, C.R.; ANGELOTTI, F.; MOURA, M.S.B. Vitis vinifera spectral response to the increase of $\mathrm{CO}_{2}$. Journal of Hyperspectral Remote Sensing, Recife, v. 1, p. 1-18, 2011.

GARIGLIO, M.A.; SAMPAIO, E.V.S.B.; CESTARO, L.A.; KAGEYAMA, P.Y. Uso sustentável e conservação dos recursos florestais da Caatinga. Serviço Florestal Brasileiro: Brasília, 2010. 368 p.

GIONGO, V.; CUNHA, T.J.F.; MENDES, A.S.M.; GAVA, C.A.T. Carbono no sistema solo-planta no Semiárido brasileiro. Revista Brasileira de Geografia Física, Recife, v. 4, n. 6, p. 1233-1253, 2011.

GRACE, J.H. Role of forest biomes in the global carbon balance. In: GRIFFITHS, H.; JARVIS, P.G. (Eds). The carbon balance of forest biomes. Edinburg: Taylor \& Francis, 2005. p. 19-47.

HEINSCH, F.A.; REEVES, M.; VOTAVA, P.; KANG, S.; MILESI, C. et al. User's Guide - GPP and NPP (MOD17A2/A3) Products. NTSG, University of Montana, version 2.0, December 2, 2003.

HOLANDA, A.C.; LIMA, F.T.D.; SILVA, B.M.; DOURADO, R.G.; ALVES, A.R. Estrutura da vegetação em remanescentes de caatinga com diferentes históricos de perturbação em Cajazeirinhas (PB). Revista Caatinga, Mossoró, v. 28, n. 4, p. 142-150, 2015.

INSTITUTO BRASILEIRO DE GEOGRAFIA E ESTATÍSTICA (IBGE). Manual técnico da vegetação brasileira. 2 . ed. Rio de Janeiro: IBGE, 2012. 275p.

IPCC. Climate Change 2014: Synthesis Report. Contribution of Working Groups I, II and III to the Fifth Assessment Report of the Intergovernmental Panel on Climate Change [Core Writing Team, R.K. Pachauri and L.A. Meyer (eds.)]. Geneva, Switzerland: IPCC, 2014, 151p.

KAUFFMAN, J.B.; HUGHES, R.F.; HEIDER, C. Carbon pool and biomass dynamics associated with deforestation, land use, and agricultural abandonment in the neotropics. Ecological Applications, Tempe, v. 19, n. 5, p. 1211-1222, 2009.

KOEHLER, H.S.; WATZLAWICK, L.F.; KIRCHNER, F.F. Fontes e níveis de erros nas estimativas do potencial de fixação de carbono. In: SANQUETTA, C.R.; WATZLAWICK, L.F.; BALBINOT, R. (Ed.). As florestas e o carbono. Curitiba: FUPEF/Imprensa da UFPR, 2002. p. 251-264.

LIU, S; KAIRE, M; WOOD, E; DIALLO, O; TIESZEN, L.L. Impacts of land use and climate change on carbon dynamics in south-central Senegal. Journal of Arid Environments, London, v. 59, n. 3, p. 583-604, 2004. 
MARENGO, J.A. Vulnerabilidade, impactos e adaptação à mudança do clima no semi-árido do Brasil. Parcerias Estratégicas, Brasília, v. 13, n. 27, p. 149-176, 2008.

MINISTÉRIO DA CIÊNCIA E TECNOLOGIA (MCT). Inventário brasileiro das emissões e remoções antrópicas de gases de efeito estufa. Brasília, 2009. Disponível em: http://www.mct.gov.br/index.php/content/view/4006.html. Acesso em: 18 de janeiro de 2015.

MINISTÉRIO DA CIÊNCIA, TECNOLOGIA E INOVAÇÃO (MCTI). Estimativas anuais de emissões de gases do efeito estufa no Brasil. 2. ed. Brasília, 2014. Disponível em: http://www.mct.gov.br/index.php/content/view/347281.html. Acesso em: 18 de janeiro de 2015.

MINISTÉRIO DO MEIO AMBIENTE (MMA). Monitoramento do Bioma Caatinga. Brasília: MMA, 2010. Disponível em: http://www.mma.gov.br/estruturas/sbf_chm_rbbio/_arquiv os/relatrio_tcnico_caatinga_72.pdf. Acesso em: $26 \mathrm{de}$ setembro de 2013.

PROJETO DE CONSERVAÇÃO E UTILIZAÇÃO SUSTENTÁVEL DA DIVERSIDADE BIOLÓGICA BRASILEIRA (PROBIO). Mapas de Cobertura Vegetal dos Biomas Brasileiros. 2008. Disponível em: http://mapas.mma.gov.br/mapas/aplic/probio/datadownloa d.htm?/caatinga/documentos/. Acesso em: 9 de setembro de 2013.

SAMPAIO, E.V.S.B.; COSTA. T.L. Estoques e fluxos de carbono no Semiárido Nordestino: estimativas preliminares. Revista Brasileira de Geografia Física, Recife, v. 4, n. 6, p. 12751291, 2011.

SANTOS, V.S.; PACHECO, S.M.; FERREIRA, C.J.M.; NÓBREGA, R.S. ;SILVA, O.G. Seca no Nordeste e os sistemas atmosféricos de escala global: o caso de Serra Talhada - PE. In: GALVIINCIO, J.D.; SOUZA, W.M. de (Ed.). Mudanças climáticas e biodiversidade. Recife: Editora Universitária da UFPE, 2013. p. 371-393.

SANTOS, J.C; LEAL, I.R.; ALMEIDA-CORTEZ, J.S.; FERNANDES, G.W.; TABARELLI, M. Caatinga: the scientific negligence experienced by a dry tropical forest. Tropical Conservation Science, Menlo Park, v. 4, n. 3, p. 276-286, 2011.

SANTOS, A.M.; TABARELLI, M. Distance from roads and cities as a predictor of habitat loss and fragmentation in the caatinga vegetation of Brazil. Brazilian Journal of Biology, São Carlos, v. 62, n. 4b, p. 897-905, 2002.

SCHAEFFER, M.; EICKHOUT, B.; HOOGWIJK, M.; STRENGERS, B.; VAN VUUREN, D. et al. $\mathrm{CO}_{2}$ and albedo climate impacts of extratropical carbon and biomass planta- tions. Global Biogeochemical Cycles, Washington, v. 20, n. 2, p. 1-15, 2006.

SILVA, B.B. Estimativa de sequestro de carbono por sensoriamento remoto. In: GALVÍNCIO, J.D. (Ed.). Mudanças climáticas e modelo ambientais: caracterização e aplicações. Recife, BRA: Editora Universitária da UFPE, 2012. p. 51-70.

SILVA, B.B.; GALVÍNCIO, J.D.; MONTENEGRO, S.M.G.L.; MACHADO, C.C.M.; OLIVEIRA, L.M.M. et al. Determinação por sensoriamento remoto da produtividade primária bruta do perímetro irrigado São Gonçalo - PB. Revista Brasileira de Meteorologia, São José dos Campos, v. 28, n. 1, p. 57-64, 2013.

SOUZA, B.I.; ARTIGAS, R.C.; LIMA, E.R.V. Caatinga e Desertificação. Mercator, Fortaleza, v. 14, n. 1, p. 131-150, 2015.

SPIELAGEN, R.F. Hotspots in the Arctic: Natural archives as an early warning system for global warming. Geology, Boulder, v. 40, n. 11, p. 1055-1056, 2012.

TROVÃO, D.M.B.M.; FERNANDES, P.D.; ANDRADE, L.A.; DANTAS NETO, J. Variações sazonais de aspectos fisiológicos de espécies da Caatinga. Revista Brasileira de Engenharia Agrícola e Ambiental, Campina Grande, v. 11, n. 3, p. 307-311, 2007.

YU, D., SHI, P., SHAO, H., ZHU, W., PAN, Y. Modelling net primary productivity of terrestrial ecosystems in East Asia based on an improved CASA ecosystem model. International Journal Remote Sensing, v. 30, n. 18, p. 4851-4866, 2009.

ZHANG, Y.; SONG, C.; ZHANG, K.; CHENG, X.; ZHANG, Q. Spatial-temporal variability of terrestrial vegetation productivity in the Yangtze River Basin during 2000-2009. Journal of Plant Ecology. v. 7, n. 1, p 10-23, 2014.

\section{Endereços de internet}

DISTRITO DE IRRIGAÇÃO NILO COELHO (DNIC). Disponível em: http://dinc.org.br/. Acesso em: 26 jan. 2014.

EMPRESA BRASILEIRA DE PESQUISA AGROPECUÁRIA (EMBRAPA). Dipsponível em: http://www.cpatsa.embrapa.br:8080/index.php?op=dadosmet. Acesso em: 2014.

INSTITUTO BRASILEIRO DE GEOGRAFIA E ESTATÍSTICA (IBGE). Censo Demográfico 2010. Disponível em: http://www.ibge.gov.br/. Acesso em: 15 fev. 2012.

This is an Open Access article distributed under the terms of the Creative Commons Attribution Non-Commercial License which permits unrestricted non-commercial use, distribution, and reproduction in any medium provided the original work is properly cited. 